TE WHARE WĀNANGA O TE ŪPOKO O TE IKA A MĀUI
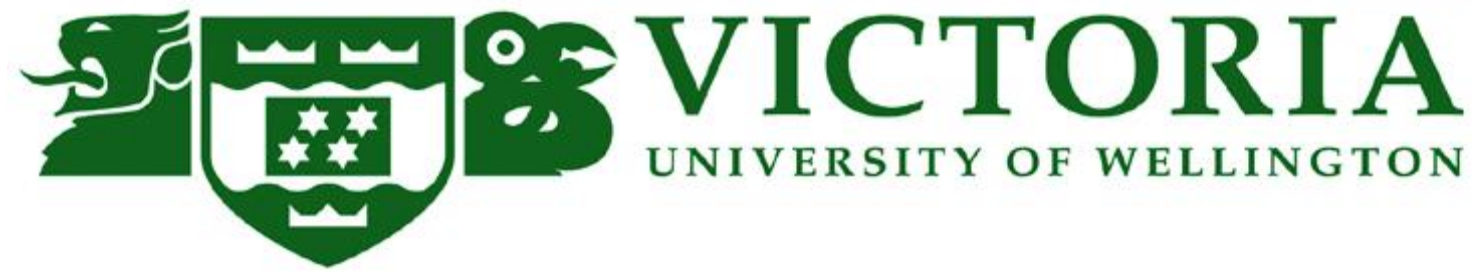

UNIVERSITY OF WELLINGTON

\title{
Evaluating the user perceived usefulness of Enterprise Social Networking
}

by

\section{Naveen Vaseegaran}

\begin{abstract}
Submitted to the School of Information Management, Victoria Business School, Victoria University of Wellington in partial fulfilment of the requirements for the degree of Master of Information Management
\end{abstract}




\section{Table of Contents}

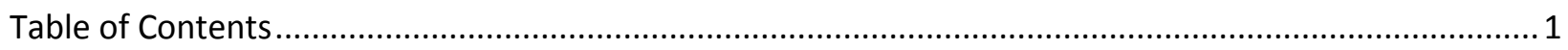

Abstract

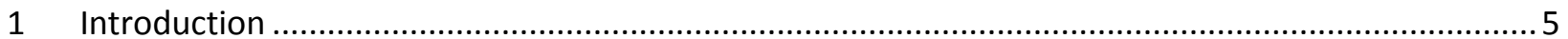

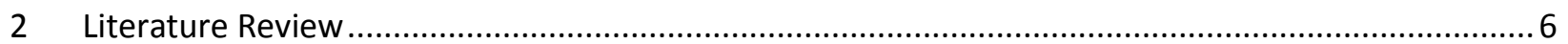

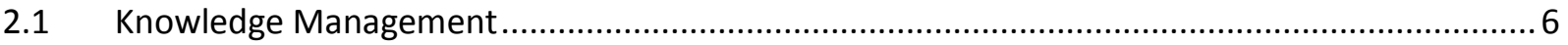

2.2 Usefulness of Knowledge Management …........................................................................ 8

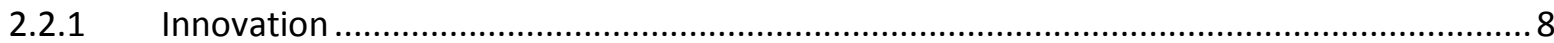

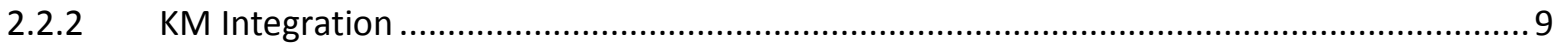

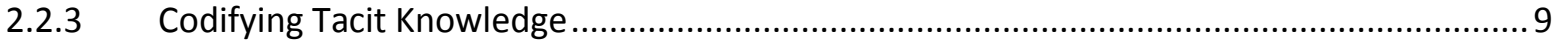

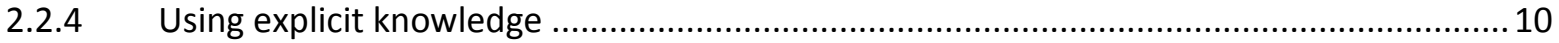

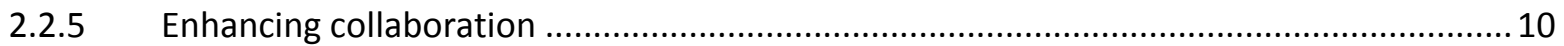

2.3 Enterprise Social Networking and Knowledge Management ................................................. 11

2.3.1 ESN is more social - codifies tacit and explicit knowledge ............................................. 11

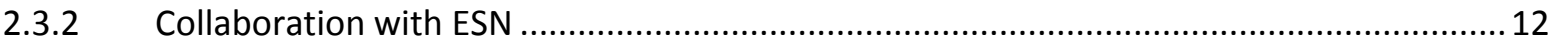

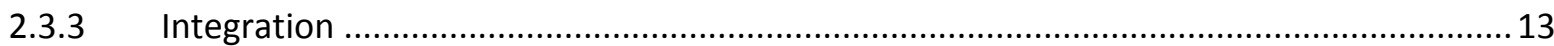

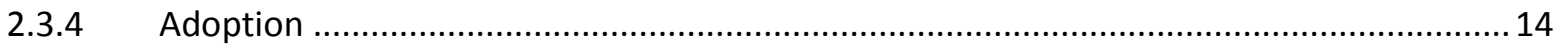

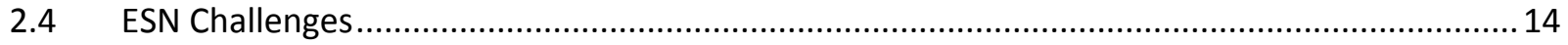

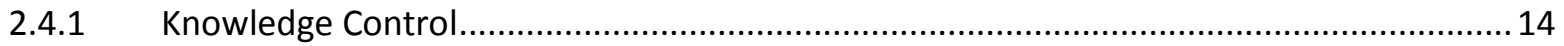

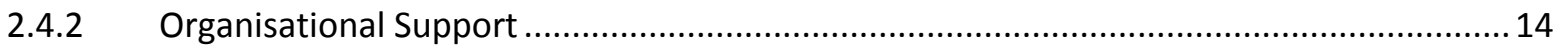

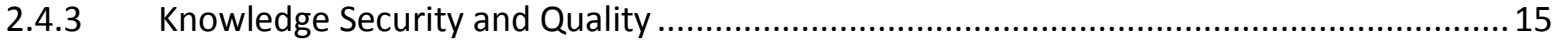

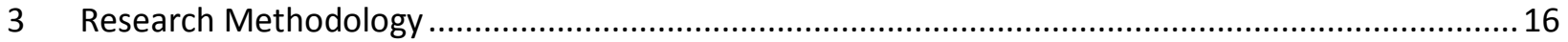

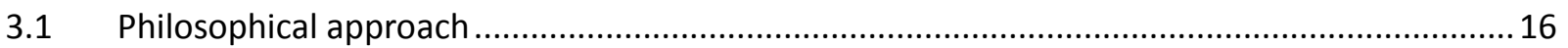

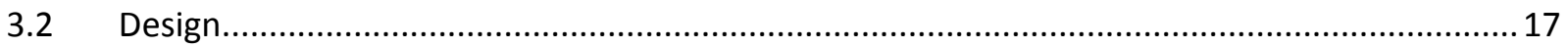

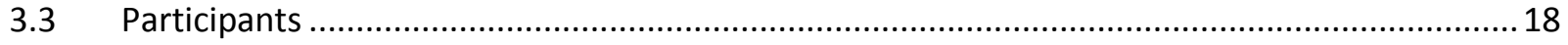

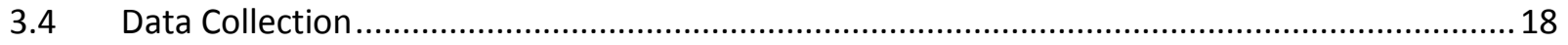

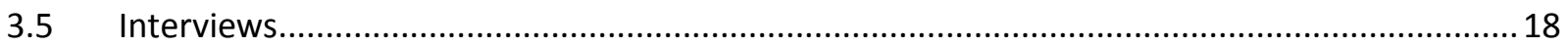

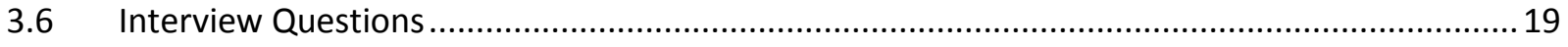

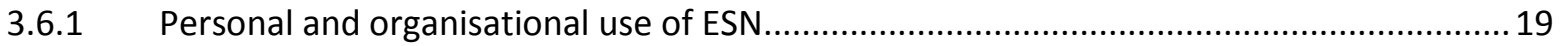


EVALUATING THE USER PERCEIVED USEFULNESS OF ENTERPRISE SOCIAL

NETWORKING

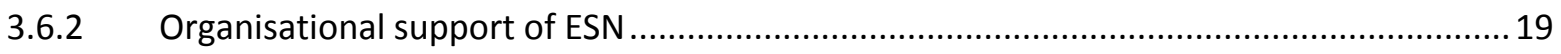

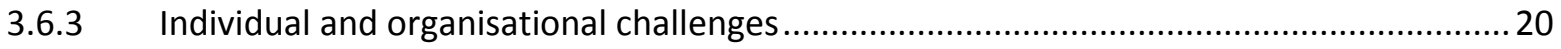

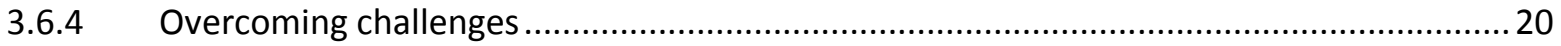

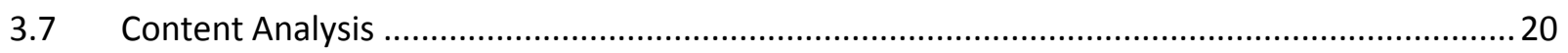

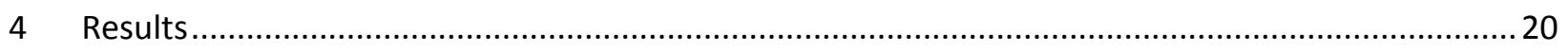

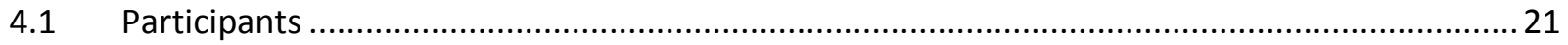

$4.2 \quad$ ESN use

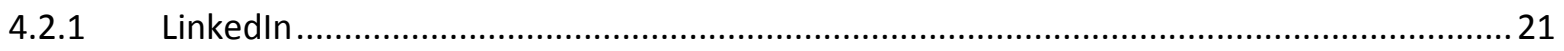

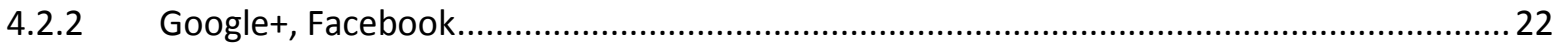

4.2.3 Yammer and other bespoke ESN software .................................................................. 22

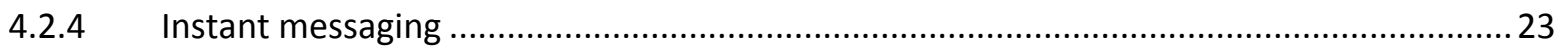

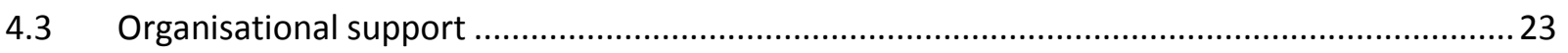

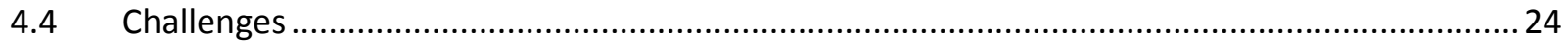

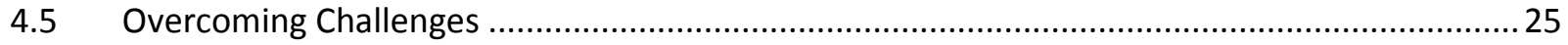

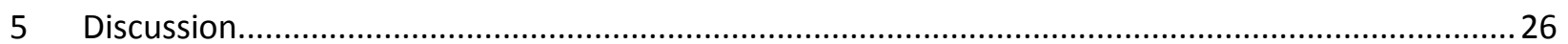

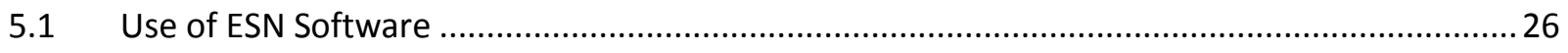

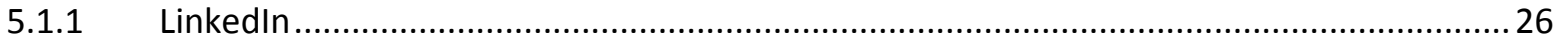

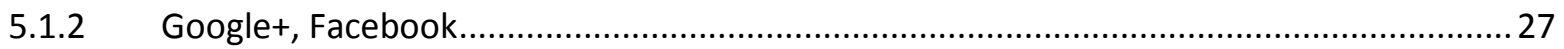

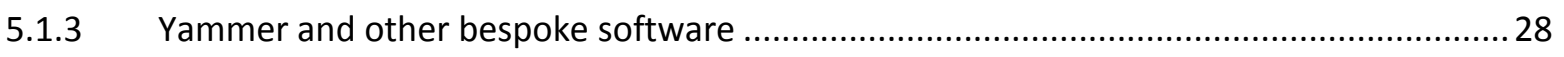

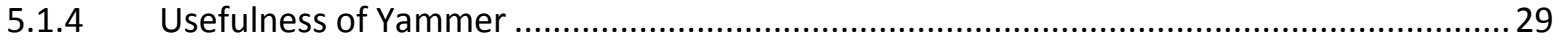

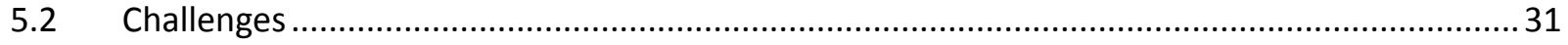

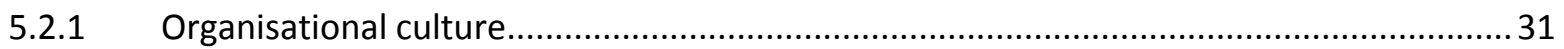

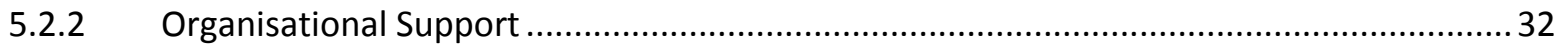

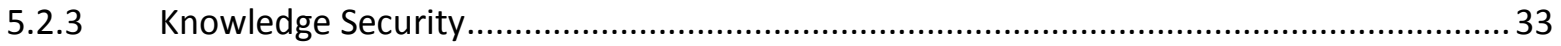

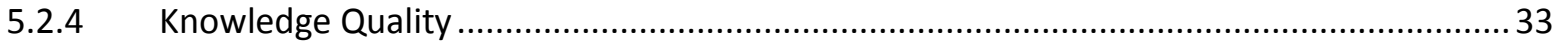

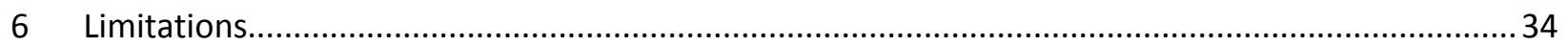

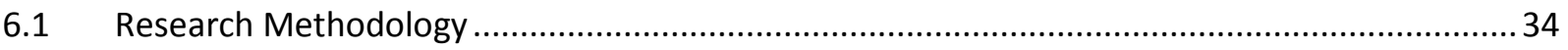

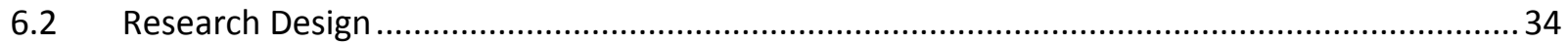

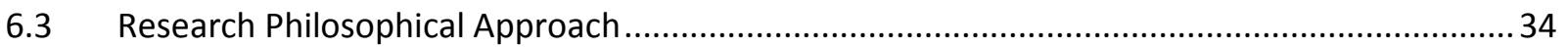

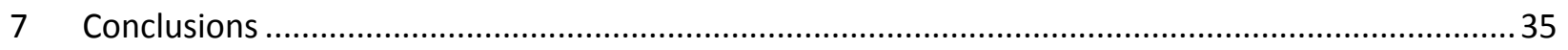

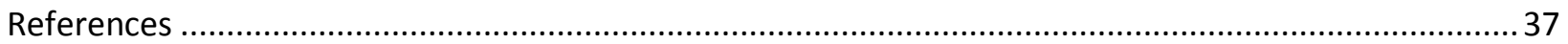


EVALUATING THE USER PERCEIVED USEFULNESS OF ENTERPRISE SOCIAL NETWORKING

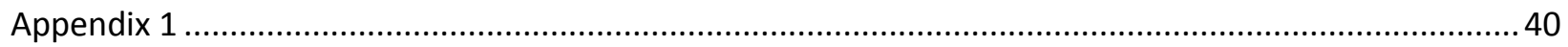

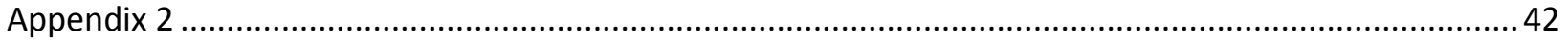

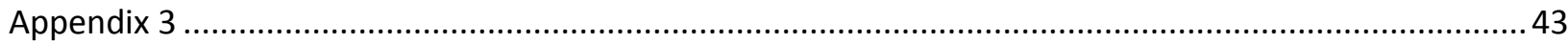

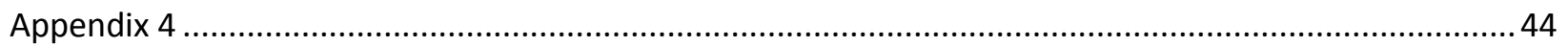

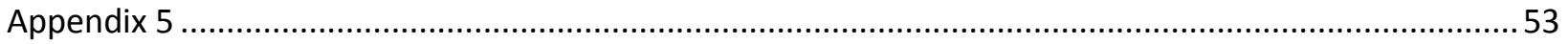


EVALUATING THE USER PERCEIVED USEFULNESS OF ENTERPRISE SOCIAL NETWORKING

\section{Abstract}

This paper aims to identify user perceived usefulness of enterprise social networking within the public and private sector of Wellington NZ. It aims at determining the specific factors that appeal to enterprise social networking users. This paper first outlines the global trend towards enterprise social networking based on academia and IT industry papers. It draws parallels between ESN and KM to better understand the unique attributes of ESN. In particular it brings to focus the social nature of ESN and the use of modern technologies that facilitate ease of use. It also highlights the community nature of ESN and its importance in managing knowledge security, quality, trust and sense of sharing. These dimensions help form the basis on which the interview questions are based. Anti- positivism philosophical approach is used to peer into user perceptions and make sense of the research findings.

Qualitative data shall be gathered through interviews. 7 participants will be involved in the interviews. Participants will be a mixture of MIM students and IT professionals employed within the private and public sector.

The outcome of this study is to better understand contemporary views on the topic and shape future direction in better dissemination of enterprise social networking in the local industry. The focus on what the user perceived usefulness of social networking within wellington will give insights into user adoption strategies for enterprise social networking. 
EVALUATING THE USER PERCEIVED USEFULNESS OF ENTERPRISE SOCIAL NETWORKING

\section{Introduction}

Social networking - a creation of the modern internet has permeated well into the way people live and conduct their daily lives both professionally and personally. It is quite common amongst Facebook users to decide where to meet up for a social event through Facebook collaboration tools like profile shout out, group messaging etc. LinkedIn another social networking tool, is used by professionals to showcase their skills, connect with professional forums and discuss, all in an effort to grow their career and knowledge base. Businesses often hire individuals via LinkedIn.

Social networking is influencing enterprise businesses in knowledge management (KM), evolving from traditional monolithic and centralised Information System (IS) implementations to more human and socially focused interactions (Riemer, Scifleet, \& Reddig, 2012). Enterprise organisations have set up their own private social networking to stimulate knowledge sharing at a social level. This private social networking in the corporate environment is often termed as enterprise social networks (ESN). Modern ESN utilises Web 2.0 technologies to support a collage of social intranet tools like Wikipedia, blogs, discussion forums and instant messaging within the organisation (Faraj, Jarvenpaa, \& Majchrzak, 2011). Advanced features include multimedia, user-tagging and user profiles. It is much more than just codifying tacit knowledge, it attempts to bring disparate communities within the organisation together. Culturally it also attempts to move away from a hierarchical organisation to a flat organisation where everyone's opinion is valued and taken note (DiMicco et al., 2008). Yammer a successful ESN tool has been adopted by over 200,000 companies worldwide, including a number of large scale organisations like Cap Gemini and Xerox (Yammer, 2014). Yammer allows corporate users to communicate socially and effectively across physical boundaries and facilitate open collaboration, listen to conversations that matter, find the right expertise for the task at hand and empowers the employee with a voice.

ESN has been described has the new generation of KM tools, an evolution from traditional KM with similarities and contrasting differences. To understand ESN, this paper will first define, and analyse KM. This will provide the theoretical underpinning with which ESN will be analysed, compared and critiqued. 
EVALUATING THE USER PERCEIVED USEFULNESS OF ENTERPRISE SOCIAL NETWORKING

The paper will then briefly discuss the research method selected for the project. Research will be conducted within the private and public sector IT Industry groups to understand the current perceived usefulness of enterprise social networking within Wellington. Interviews will be used to collect user perceptions. This will include: What is the local user perception on ESN? Is it a fad that will pass? Is it another piece of technology they have to get their head around? The results will be discussed and analysed to help understand the perceived organisational and user challenges to ESN. It is hoped that this new understanding may help in better dissemination of ESN in Wellington.

\section{Literature Review}

\subsection{Knowledge Management}

Knowledge Management (KM) has had long history and has existed in the form of apprenticeship, training, mentoring programs, team discussion sessions. However it was only the early 1990’s KM was increasingly treated as a discipline (Nonaka, 1994).

Many definitions have been outlined to describe KM. Newman (1991) describes KM as a collection of processes that govern the creation, dissemination and utilisation of knowledge. Santosus and Surmacz (2001) suggest that KM generates value from knowledge based assets like human capital and knowledge repositories by sharing knowledge across the organisation and with other companies to help create best practices. Emery (1999) argues that the goal of KM is to manage data, information, and explicit knowledge while simultaneously leveraging and strengthening tacit knowledge through technology and KM practices.

Polanyi (1967) introduced the notion of tacit knowledge. It is knowledge that the employee holds implicitly and supplemented by experience. It cannot be easily transferred or codified. Explicit knowledge on the other hand can be easily codified and communicated (Alavi \& Leidner, 2001). Zeleny (1987) proposed the knowledge hierarchy where, data is first translated to information and this information gradually turns to knowledge by 'making sense of' the data. Over time knowledge turns to wisdom. Under this hierarchy framework Zeleny (1987) argued that while organisations capture data and turn that to information it takes a whole new level of expertise and complexity to gain knowledge from that information. 
EVALUATING THE USER PERCEIVED USEFULNESS OF ENTERPRISE SOCIAL NETWORKING

However, Alavi and Leidner (2001) argue that the hierarchy from data to information to knowledge is inaccurate. They further argue that the distinguishing factor between the hierarchies is not found in the structure, content, interpretability or usefulness. They suggest that knowledge is information processed in the minds of individuals. It is cultivated through related facts, concepts, procedures, ideas, judgements and observations.

Nonaka (1994) took the idea of 'tacit knowledge' further and suggested that tacit knowledge needed to be codified to explicit knowledge. Nonaka and Takeuchi (1995) proposed the knowledge spiral Model (Fig 1.1). However it was argued the distinction between tacit and explicit knowledge was an over simplification (Serenko \& Bontis, 2004).

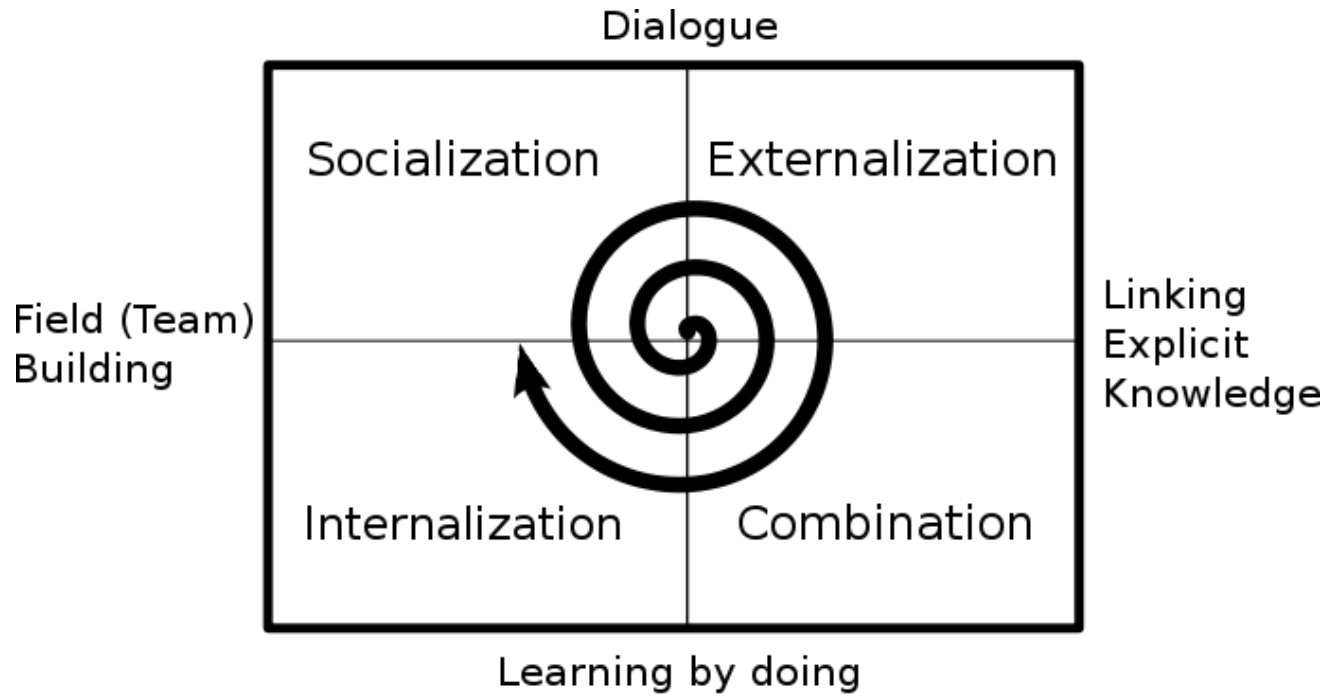

Fig 1.1 Knowledge Spiral Model (Nonaka \& Takeuchi, 1995)

In this model knowledge flows in a spiral cycle where tacit knowledge is extracted to become explicit knowledge and again gradually internalised to implicit knowledge. It is a selfgenerative process and aims to continually grow and increase the organisation's knowledge base by rooting a learning culture within the organisation. Fig 1.2 explains this notion succinctly. 
EVALUATING THE USER PERCEIVED USEFULNESS OF ENTERPRISE SOCIAL NETWORKING

TO

\begin{tabular}{|c|c|c|c|}
\hline & & Tacit Knowledge & Explicit Knowledge \\
\hline \multirow{2}{*}{ FROM } & $\begin{array}{c}\text { Tacit } \\
\text { Knowledge }\end{array}$ & $\begin{array}{l}\text { SOCIALIZATION } \\
\text { Transferring tacit knowledge } \\
\text { through shared experiences, } \\
\text { apprenticeships, mentoring } \\
\text { relationships, on-the-job } \\
\text { training, "talking at the water } \\
\text { cooler" }\end{array}$ & $\begin{array}{l}\text { EXTERNALIZATION } \\
\text { Articulating and thereby } \\
\text { capturing tacit knowledge } \\
\text { through use of metaphors, } \\
\text { analogies, and models }\end{array}$ \\
\hline & $\begin{array}{c}\text { Explicit } \\
\text { Knowledge }\end{array}$ & $\begin{array}{l}\text { INTERNALIZATION } \\
\text { Converting explicit knowledge } \\
\text { into tacit knowledge; learning } \\
\text { by doing; studying previously } \\
\text { captured explicit knowledge } \\
\text { (manuals, documentation) } \\
\text { to gain technical know-how }\end{array}$ & $\begin{array}{l}\text { COMBINATION } \\
\text { Combining existing explicit } \\
\text { knowledge through exchange } \\
\text { and synthesis into new explicit } \\
\text { knowledge }\end{array}$ \\
\hline
\end{tabular}

Fig 1.2 Knowledge conversion (Nonaka \& Takeuchi, 1995)

\subsection{Usefulness of Knowledge Management}

\subsubsection{Innovation}

Pyka (2002); Shani, Sena, and Olin (2003)suggest that innovation has a strong dependency on the availability of organisational knowledge and consequently managing the richness of organisational knowledge is key to successful innovation. Earlier research by Ruggles and Little (1997) also supports this assertion. The authors view that knowledge and innovation play an increasingly vital role in generating business value. Organisations with no internal knowledge sharing tools have difficulty in recognizing, understanding and accessing the tacit and explicit knowledge stocks inherit in the organisation. Innovation through knowledge synthesis becomes difficult if not impossible.

Gloet and Terziovski (2004) suggest that KM breeds a culture of innovation by fostering iterative cycles of knowledge sharing and creation through collaboration. The integrated approach to facilitating knowledge through KM practices encourages creativity: thinking outside of the box. This culture of innovation builds employee skills and better aligns them to innovate and make effective contributions (Scarbrough, 2003). This intersection of KM in human resource 
EVALUATING THE USER PERCEIVED USEFULNESS OF ENTERPRISE SOCIAL NETWORKING

management has positive impacts. KM is useful in highlighting the skills of internal innovation participators and helps to realign their expertise into specific innovation development where their skills are immensely helpful. Knowledge creation and sharing and the resultant innovation can not only be captured by KM but also measured. This highlights the usefulness of KM in innovation and provides instrumentation for evaluating $\mathrm{KM}$ and its role in innovation.

\subsubsection{KM Integration}

Chen, Zhu, and Xie (2004) suggest that knowledge integration refers to the creation, gathering, sharing and availability of knowledge. Knowledge integration facilitates knowledge to be organic and evolve through iterative knowledge accrual and collaboration. Badii and Sharif (2003) suggest that knowledge integration is an essential framework for knowledge to thrive and evolve within the organisation; otherwise the organisation risks efficient use of knowledge as it may be outdated, with no deep insight. It is important for KM capabilities to present this integrated knowledge to the right person at the right time (Santosus \& Surmacz, 2001). KM systems need to emulate this behaviour, otherwise innovators risk having superfluous information which paradoxically defeats KM efforts to incite innovation. Google's search engine has excelled in this domain providing only the information that user needs.

Adams and Lamont (2003) suggests that KM integration also extends to integrating the disparate knowledge repositories like intranets, databases, financial data and other electronically captured data into the core KM system. The integrated KM system plays a key role in knowledge transfer exercises which ensure that core knowledge remains within the organisation. At times of radical innovation, industry change or unpredictable market forces, the organisation maybe playing by new 'unknown' rules. KM integration facilitates the understanding of these 'unknown rules' as knowledge is encouraged to be continuously evolve in KM and expand through the confluence of historical and current tacit and explicit knowledge both within and outside the organisation.

\subsubsection{Codifying Tacit Knowledge}

Cavusgil, Calantone, and Zhao (2003) notes that innovative organisations use KM to codify tacit knowledge into explicit knowledge and help retain the lessons learnt, while on the 
EVALUATING THE USER PERCEIVED USEFULNESS OF ENTERPRISE SOCIAL NETWORKING

job. This enhances the organisation's learning by doing capabilities. The codified knowledge is shared through collaboration within the organisation to develop innovative products, services or processes.

Replication of the knowledge repository by competitors is rather difficult as it not known what social, environmental, historical, internal, external and other contextual factors led to the accrual of the knowledge (Cardinal, Alessandri, \& Turner, 2001).

\subsubsection{Using explicit knowledge}

Explicit knowledge is also an important component of KM (Scarbrough, 2003). KM collaboration process applies tacit knowledge to explicit organisational knowledge and the combination results in new knowledge. KM helps to capture the new tacit and explicit knowledge. This in turn can be useful in evolving the knowledge base. Rodan (2002) indicates that KM also helps in the accrual of knowledge from external sources- industry trends. This accrued knowledge adds on to the existing organisational knowledge, potentially creating new knowledge. KM also makes the knowledge readily accessible increasing the opportunities for the confluence of tacit and explicit knowledge elements that lead to knowledge growth.

\subsubsection{Enhancing collaboration}

KM extends internal and external collaboration efforts through technology driven tools (Cavusgil et al., 2003). KM enhances the internal collaboration efforts empowering innovators with the most succinct organisational information from which to innovate. It enables sharing knowledge across the organisation. It enables learning from previous mistakes, better understanding of what works within the organisational framework, challenges that lie ahead in the form of customer acceptance and better understanding of competitor efforts.

Pyka (2002) suggest formal business relationships give way to informal business relationships as it fosters mutual trust and confidence. KM collaboration efforts allow innovators to tap into the informal industry networks external to the organisation. The knowledge within these networks is often in tacit form and collaboration acts as the conduit to transfer this external tacit knowledge into the organisation where it is added to the existing knowledge base using KM. Microsoft, has a number of online public forums on various software technologies where 
EVALUATING THE USER PERCEIVED USEFULNESS OF ENTERPRISE SOCIAL NETWORKING

employees interact with customers, software developers, technical experts and other members of general public (Microsoft, 2014). This allows Microsoft to not only provide customer assistance but also garner tacit knowledge about new thinking in solving complex technical issues.

\subsection{Enterprise Social Networking and Knowledge Management}

KM is evolving considerably with the advent of the social software (Von Krogh, 2012). Social software has been conceived with advancements in information related technologies like broadband and Web 2.0. It develops and enables social communities to openly interact and exchange content like Facebook and LinkedIn. Social software re-directs traditional KM approach from strict managerial control over knowledge, to a more open and socially focused collaboration model, giving birth to ESN (Bebensee, Helms, \& Spruit, 2012; Paroutis \& Al Saleh, 2009). ESN encourages sharing of knowledge, information and data trough social principles (Levy, 2009; Razmerita, Kirchner, \& Sudzina, 2009). It is founded on social principles, like peer production, unbounded collaboration and the creation of knowledge sharing communities (Brivot, 2011; Muljadi et al., 2006; Riemer et al., 2012). The key advantages of traditional KM in facilitating innovation, collaboration and knowledge integration that were discussed earlier is further enhanced in ESN. This is discussed in detail, below.

\subsubsection{ESN is more social - codifies tacit and explicit knowledge}

Early knowledge management systems took a knowledge-as-object view (Alavi \& Leidner, 2001). It attempted to extract individual knowledge and codify it into the repository (Hansen, Nohria, \& Tierney, 2005). These early KM systems were characterised as people-todocument knowledge management systems. Modern KM systems or ESN has evolved from this traditional epistemology into modern knowledge-in-action view with social communities that encourage and stimulate knowledge sharing.

The KM theoretical framework - "Knowledge Conversion" discusses the importance of codifying knowledge garnered through socialisation or "Water cooler conversations" (Nonaka \& Takeuchi, 1995). Early KM, however lacks the practical application that enables the capture of these water cooler conversations and resorts to structured processes. ESN on the other hand provides the practical tools -innovative web 2.0 tools that enable rich collaboration, employee 
EVALUATING THE USER PERCEIVED USEFULNESS OF ENTERPRISE SOCIAL NETWORKING

personal knowledge management and employee connectedness (Faraj et al., 2011). It also attempts to minimise hierarchal barriers and connect employees irrespective of their hierarchal management ranking. In essence ESN brings the water cooler conversation into the purview of the ESN application. This better enables users to make informed decisions based on the rich user collaboration and help to solve tasks more efficiently. Given the strict structures early KM did not stimulate the 'community feel' and trust that ESN inherently nurtures through personal knowledge management and employee connectedness. The organisation as a whole is more connected and readily aware of what's going on through these social interactions. This 'community feel' and trust within the organisation, positively affects employees to be productive, engaging and collaborative (DiMicco et al., 2008).

\subsubsection{Collaboration with ESN}

ESN is useful in creating buzz, excitement within the organisation. The interactions are automatically codified, stored and well organised to be searchable. The knowledge base forms part of the organisation's knowledge eco-system. Opinions and other comments of employees are automatically stored in this repository. Traditional KM capabilities are limited and the collaboration thread, is often difficult to find and not very readable. Employees can always refer to the repository as the first port of call, and verify if their query has already been answered enhancing content reuse. 'Like', 'share', 'invite', 'vote' options in interactive forums, facilitates organisational engagement by making it social and non-hierarchical. Web 2.0 technologies built into ESN enable virtual worlds giving birth to new and engaging forms of collaboration, training and learning. Cisco makes use of second life for product training (Kane \& Fichman, 2009). This invites participation from employees and increases productivity. As the social connections develop, through ESN they can be analysed to support managerial decision making in identifying key contributors of knowledge, key performers and analysis of management connection networks (Cross, Liedtka, \& Weiss, 2005). Majchrzak (2007) suggests that the social connections developed between the employees contributes to enhanced innovation, managerial problem solving and improved business processes.

Wikis and blogs form a key part of the ESN toolset. They can acts as both internal and external ESN tools. Wikis and blogs help to exchange ideas, pose questions, and observe opinions in an interactive way (Brzozowski, 2009; DiMicco et al., 2008). Wikis and blogs utilise 
EVALUATING THE USER PERCEIVED USEFULNESS OF ENTERPRISE SOCIAL NETWORKING

web 2.0 technology to maximise ease of use and intuitiveness - key characteristics of socially oriented principles. They also capture key contributors of knowledge - facilitating networks of "Creators". Through numerous iterations and content ratings the network of "creators" evolve content into a substantial and useful source of knowledge (Bloodgood \& Salisbury, 2001). This diminishes the need for a more structured ontology based knowledge repository advocated by traditional KM. Blogs are also useful to peer into innovative trends, put forward ideas and business cases, gather momentum, support and feedback through interaction, all without hierarchical barriers.

\subsubsection{Integration}

ESN has the flexibility to socialise and gather knowledge for specific business functions like Marketing and Sales, human resource management and research and development (Li \& Bernoff, 2011). Depending on the business function ESN can be internal to the organisation or external. External ESN networks (Wikis, blogs, and twitter) help the organisation to connect with external customers, suppliers and knowledge experts. Marketing ESN, act as external communication channels to customers. It is used to provide product information and availability, create buzz on new products, develop brand and vendor recognition and create customer trust (Drury, 2008). The customer interactions provide valuable feedback through customer ratings, reviews and recommendations. This valuable information is then used for product improvement. External ESN also helps build communities around key products like Coca-Cola. This, not only helps create new connections with customers but also gauge sales leads with business partners (Roberts, 2008).

SilverStripe (2014) has cultivated a community around its core product - Content Management System (CMS). This has given them tremendous exposure, enabling successful business partnership with Google. Also the Internal technical staff, continuously interact with external experts through forums and other external ESN channels. This enables SilverStripe to not only garner customer feedback but also expert community knowledge and improve their product. Mozilla (2014) also provides ESN tools that focuses on research and development. The ESN allows external experts to contribute to various open source projects. In fact, these projects thrive on the open developer community for expert knowledge. Key contributors within this community also often grow with Firefox with more responsibility. 
EVALUATING THE USER PERCEIVED USEFULNESS OF ENTERPRISE SOCIAL NETWORKING

\subsubsection{Adoption}

Research on technology acceptance model suggests that training is key to successful adoption of traditional KM (Venkatesh, Morris, Davis, \& Davis, 2003). ESN on the other hand, is based on social software like Facebook, Wikis that have already proliferated widely and sensitised users to the new ounces of web 2.0 and it's plethora of social features, design and limitation. ESN rides on this familiarity and consequently is easier to disseminate within employees, costing less to adopt than the traditional KM.

\subsection{ESN Challenges}

\subsubsection{Knowledge Control}

ESN is not without inherent difficulties and risks and has strategic implications (Haefliger, Monteiro, Foray, \& Von Krogh, 2011). Some of them are outlined below. Traditional KM strictly manages knowledge to maintain organisational confidentiality and competitive advantage over rivals. It defines strict structures, policies and management resources to govern the evolution of knowledge and its strategic value. This boundary protection and compartmentalisation of knowledge provided by traditional KM is absent in ESN. With ESN, the organisation does not have much control over how knowledge or what type of knowledge evolves. Also the partitioning, prioritisation of knowledge and its accessibility within ESN is difficult. The core principle of social software on which ESN is based - free and unfettered flow of knowledge amongst user interactions (Jeppesen \& Frederiksen, 2006) is a double edged sword. In other words, the free flow of knowledge encouraged by ESN, also hinders control of that knowledge. Haefliger et al. (2011) argue that whilst it is possible to incite prudence amongst users and monitor knowledge flow, it may be impractical as it contradicts with the philosophy of $\mathrm{ESN}$ - free flow of Knowledge.

\subsubsection{Organisational Support}

ESN requires the organisational wide acceptance and also the support of management to be a success within the organisation (Brzozowski, 2009). Though ESN is largely popular amongst the younger generation (Levy, 2009) it requires training with the older generation. Strong management support, who freely evangelise blogging and other related social activities is pivotal to ESN success. Without large knowledge sharing communities, the essence of ESN is largely lost. ESN success is proportional to the contributions and social networking within ESN. 
EVALUATING THE USER PERCEIVED USEFULNESS OF ENTERPRISE SOCIAL NETWORKING

For instance, members use ESN to connect with other knowledge experts. There would be little incentive if these knowledge experts did not use ESN.

\subsubsection{Knowledge Security and Quality}

Social practices inherit within ESN encourage organisations to share information with other external entities for a number of reasons. Some organisations share information in hopes that, a solution may be revealed from anonymous source/s for a monetary fee (Sieg, Wallin, \& Von Krogh, 2010). Sieg et al. (2010) argue that when an organisation shares information with external sources, it risks exposing critical information that could potentially allow its competitor to leap frog the technology hurdle and gain significant advancements. Also the organisation may undergo internal process changes to accommodate the external solution, affecting the firm's unique competitive advantage capability.

Other organisations may use external information within their ESN to make decisions, innovate, discuss or provide services. This also creates risks. The owner of the external intellectual property may not be aware of the organisation's use of this information. The organisation could potentially be committing intellectual property theft. In other situations the information present internally as personal data i.e. individual blogs, photos, personal documentation may be deemed as corporate data. However it may be protected by intellectual rights of the owner.

Quality and accuracy of information provided by users of ESN is also a concern (Chai, Potdar, \& Dillon, 2009). For instance, what is the validity and accuracy of user generated content in Wikipedia? Is the information acquired legally and ethically? Chai et al. (2009) argue that ESN lacks rigour and sound evidence of the data that is contributed. However Von Krogh, Haefliger, Spaeth, and Wallin (2012) argue that peer social practices inherent within ESN will advocate the validation of content that is specific to the problem, task and project goals. It will also ensure that content conforms to the organisation's ethical, cultural and strategic values. For instance, organisations that share information to external agencies will do so with prudence, the

peer community will adjudicate how the information is used and ensure acknowledgement to the owner/s of the intellectual property. The Wikipedia peer community moderate content and ensure all information is referenced to the source and the original author or content provider is 
EVALUATING THE USER PERCEIVED USEFULNESS OF ENTERPRISE SOCIAL NETWORKING

acknowledged. Likewise the peer community of organisations that use external sources of information will monitor the ESN repository and ensure that whenever external information is used it will be clearly acknowledged and any rights to use that information is sought. The peer community within these organisations will also ensure that the information that is either shared or externally sourced is accurate, valid, fit for purpose, meets the needs of the project or helps in the decision making process or makes a contribution to the innovation of the organisation. Working alongside the organisation the peer community will evolve the social practices on personal knowledge management to have a better understanding of the boundaries of personal information and the interplay between organisational owned knowledge and personal knowledge protected by intellectual rights. In essence peer community will govern and cultivate the social practices of the organisation and will form the basis of a cohesive entity in refining the tacit and explicit knowledge contributed through ESN.

\section{Research Methodology}

\subsection{Philosophical approach}

This research focuses to understand the user perceptions of ESN. It requires a subjective interpretation. Specifically, this research requires to make sense of each participant's perception of reality .i.e. usefulness of ESN, based on their specific experiences, cultures, values, expectations and sense of right and wrong. Based on this sense making, conclusions can be drawn on the general perception of users on the research question. Anti-positivism will be the philosophical approach for this research. This approach aligns to the 'subjective interpretation' requirement of this research (Eriksson \& Kovalainen, 2008). Anti-positivism proposes that a subjective interpretation be adopted to understand social science phenomenon (Hatch \& Cunliffe, 1997). It takes into account, each individual's perception of reality. Anti-positivism also recognises that this perception that is developed over time can change as societal norms change, and new experiences are witnessed. Based on this approach, the research will focus to understand the opinions and perceptions of the users in this research. Essentially Antipositivism, will be applied to get into the mind of the user to understand their perception of reality. 
EVALUATING THE USER PERCEIVED USEFULNESS OF ENTERPRISE SOCIAL NETWORKING

\subsection{Design}

The literature review provides the context and understanding of the theoretical underpinnings of ESN. In particular the analysis between ESN and KM as highlighted the social nature of ESN, the community feel and trust that encourages knowledge sharing. It is from this standpoint the researcher elects a number of key theoretical dimensions within ESN. The selection of these theoretical dimensions has been too fold: first identify key proponents of ESN, second from this set, identify the dimensions that when put together and researched, provide a cohesive understanding to the research question. The dimensions are detailed in section 3.6 Interview Questions.

The selected dimensions form the basis on which research is conducted. They are explored and challenged during the research process against real world practical use of ESN. For instance, one of the areas of interest is the personal and professional use of ESN. The literature review indicates how individuals use ESN. The research process gathers data about this dimension from participants. The collected data is then used to validate whether the theoretical assertions indicated, is valid and supported.

The research process applies qualitative methodology, semi-structured interviews to collect data. The collected data will be used to evaluate and discuss findings. The research process also applies the anti-positivism philosophical approach in the interview and content analysis phase of the research process.

The research has been granted ethical approval from Victoria University, Wellington, and Human Ethics Committee (HEC). Consequently, the research process operates under the guidelines indicated by the HEC. Participants were provided with the 'Participant Information Sheet' (see attached participant information sheet, Appendix 1). It describes the purpose and outcome of the research, how the data was collected, used and will be destroyed, what identifiable information was collected if any, and who will have access to the confidential data. Procedure to exit the research abruptly was also indicated if the participant wished to do so. Participants were requested to sign consent forms that ensure that the ethical process followed by the research is understood and adhered to (see attached participant consent form, Appendix 2). 
EVALUATING THE USER PERCEIVED USEFULNESS OF ENTERPRISE SOCIAL NETWORKING

\subsection{Participants}

Participants were a mixture of MIM students and IT professionals based in Wellington and employed within the private and public sector. The participants were primarily from IT groups - technology meet-up groups, and students from the MIM programme, Victoria University, Wellington. Key characteristics of participants were good exposure, and background to information technology within the wellington Information technology industry. Initial contacts were established through technology groups and suitable participants short-listed based on the characteristics. Subsequently, key personnel were approached with an outline of the proposed research and their permission sought to collect their data. The data collected were and are kept confidential, and viewed only by the research analyst and the supervisor.

\subsection{Data Collection}

Qualitative semi-structured interviews were conducted to collect data. 7 participants were involved in the interviews. Participation has been voluntary and confidential. The interviews have been around 20 minutes and the conversation voice-recorded and transcribed (see attached interview transcripts, Appendix 4). The interviews were conducted face to face and on the premises of the organisation.

\subsection{Interviews}

Anti-positivism has provided the philosophical back drop to frame the qualitative interview questions. Under this approach the interviewer motivated the interviewees to reveal their attitudes, beliefs and behaviours on the topic. Questions were focused in understanding their reality, opinions and perceptions and build the context around their thinking.

Questions weren't too specific, so as to enable free flow of thoughts. For instance, rather than framing questions around specific capabilities of ESN - knowledge integration or collaboration, questions were more general like, "In what way does ESN help to do your job better?”. It also minimises researcher bias. In situations where the interviewee has shown indepth knowledge on the topic, the interviewee has been encouraged to discuss their viewpoints in order to gain new insights. In situations where the interviewee was off topic dialogue has been used to direct discussion back to topic. The questions have also been designed such that it did not 
EVALUATING THE USER PERCEIVED USEFULNESS OF ENTERPRISE SOCIAL NETWORKING

inadvertently influence interviewee's perception like, “ESN hasn't been well integrated into existing knowledge management do you agree?"

\subsection{Interview Questions}

The purpose of the interview questions has been to collect data on the respondent's perceptions on the specific theoretical dimensions that has been identified during the literature review process (see attached interview questions, Appendix 3).

The knowledge gleaned from the literature review has provided the general boundary of questioning. Based on the literature review specific dimensions within ESN have been selected. These dimensions formed the basis on which interview questions were framed. These dimensions are given below:

\subsubsection{Personal and organisational use of ESN}

Participants were questioned on what they thought was ESN and what were some of the features and tools they used both personally and professionally at their work place. Information on general user satisfaction, and the information quality provided by was also inquired. This line of questioning helps gauge their initial understanding of ESN. Their usage patterns help demonstrate their fluency with ESN. Participants that demonstrated good understanding where motivated to provide more in-depth view points on the ease of use, frequency of use and some of the personal usefulness.

\subsubsection{Organisational support of ESN}

Questions were asked on the organisational support they received with using ESN tools. These included training that was provided, organisational culture, integration strategy of ESN into the daily work processes and other strategies the organisation may have taken to popularise ESN. Questions were also asked that probed what the participant thoughts where about the organisational efforts and support towards ESN. The framing of these questions allowed the researcher to determine the efforts of management in making ESN a success within the organisation. Also it helped understand the influencing factors that organisational management may have had in shaping the perceptions of the participant. 
EVALUATING THE USER PERCEIVED USEFULNESS OF ENTERPRISE SOCIAL NETWORKING

\subsubsection{Individual and organisational challenges}

Participants were encouraged to detail what they thought where the challenges if any to the use of ESN both from the organisational and individual perceptive. These questions help understand the level of difficulties (if any) the organisation or the individual is facing with ESN.

\subsubsection{Overcoming challenges}

Participants have been inquired about what steps they thought, where required to further promote ESN within the organisation and overcome the challenges. This understanding helps identify participant knowledge and eagerness in working with ESN at an organisational level.

The four dimensions together help form a cohesive structure of enquiry to understand the perceptions of the participant. It also provides the background context to help illustrate why the participant may have a particular viewpoint. For instance understanding the organisational support helps understand the context under which the participant has engaged with ESN. Collecting data on the challenges and the possible mitigation strategies helps to understand the context behind the level of eagerness to promote ESN.

\subsection{Content Analysis}

The interview transcripts were analysed for distinctive key phrases, ideas and concepts. In order to facilitate this process, the responses have been tabulated under the four dimensions Personal and Organisational use of ESN, Organisational support of ESN, Individual and organisational challenges and overcoming challenges. This tabulation denotes key phrases, ideas and common keywords across the dimensions for each participant. Based on this tabulation, a summary of the responses has been developed (see attached interview response themes, Appendix 5).

\section{Results}

The study results are presented as a summary of the interviews held with 7 participants. The main themes to come out were, ESN Use, Organisational support, organisational and individual challenges and lastly overcoming challenges. This is discussed below: 
EVALUATING THE USER PERCEIVED USEFULNESS OF ENTERPRISE SOCIAL NETWORKING

\subsection{Participants}

Participant's background in Information technology played a key factor in the quality of the responses. Participants who had limited career experience working in the information technology industry did not appear to provide in-depth view points on ESN. However they very savvy with personal social software like Facebook, LinkedIn, and Spotify. Personal cultural background and differences had no merit in the quality of the responses. It has been difficult to ascertain if age had any effect in the use and understanding of ESN. This could be potentially because of the small sample rate that lacked age diversity.

Participants generally understood ESN. Participant generally were eager to learn and use ESN. Participants talked about features and aspects of ESN that indicated good depth of knowledge. They were aware of how ESN might be useful to them and how it impact the organisation. They were also knowledgeable in suggesting ways to overcome challenges that they or their organisation were facing.

\subsection{ESN use}

\subsubsection{Linkedln}

Participants indicated that LinkedIn, was often used by them and their organisation. Though the data is not controlled by the organisation, it appeared to be a valuable recruitment tool for the organisation. The human resource team often profiled prospective candidates and their network via LinkedIn. Organisations often advertise via LinkedIn for new positions. Some organisations also engage with the LinkedIn community members via blogs. However, participants indicated that LinkedIn was largely seen as a recruitment tool through social and professional networking.

For the participant it was tool to showcase their skillset and build professional contacts to help build their career network. Members connected with work colleagues, previous bosses to keep professional contacts, possible references, and other career building initiatives. Some of the members engaged in LinkedIn groups and contributed to discussions. 
EVALUATING THE USER PERCEIVED USEFULNESS OF ENTERPRISE SOCIAL NETWORKING

\subsubsection{Google+, Facebook}

Few participants have indicated that their organisation had a presence in the social media space (google+, Facebook), using it as a channel to communicate with customers. However they haven't been extensively used. One banking institution has taken on to Facebook. They have maintained a followership, with a professional medium of communication. Content is updated once fortnightly. It has been noted that this organisation had difficulty in getting value out of the social medium. The respondent has indicated that in spite of all the hard work, customers don't really appreciate the level of work put into the Facebook communication channel.

\subsubsection{Yammer and other bespoke ESN software}

Participants have mentioned that not much organisations have taken on board the full capability of ESN. The three organisations that have taken on Yammer and other similar software are essentially testing the water. Participants have mentioned that the key features they had used, was limited to sharing posts, likes on posts and post comments. Individual profile data was also fairly limited. Content was largely work related rather than personal engagement. Data analytics was in place however given the limited content not much has come of it. Communication was still largely professional with little to no socialising aspect.

While the participants have noted that they are still in in the early stages of using ESN, some of the perceived benefits they mentioned include enhanced collaboration, codifying of tacit knowledge and social knowledge sharing. One of the participants said

"Sometimes important conversation gets lost and cannot be often retrieved, with ESN this conversation can be shared and further discussed with other stake holders"

This participant also felt that given the social and informal context, people would be more collaborative. Another participant mentioned that ESN integration between various government sectors would enable increased knowledge flow, leading to business efficiencies.

One particular participant: Adam, mentioned that his organisation has been quite successful with Yammer. In fact it was one of the first test organisations to implement ESN on a global platform. This participant indicated that Yammer has been fully integrated into the fabric of the organisation, people often bounced ideas over Yammer. Yammer had rich content in this 
EVALUATING THE USER PERCEIVED USEFULNESS OF ENTERPRISE SOCIAL NETWORKING

organisation. It was used regularly throughout the day. Collaboration, document sharing, keeping up with conversations that mattered were some of the ways the participant benefited from ESN.

Adam's organisation used ESN as a mechanism to grow and accrue knowledge within its internal environment. It utilised the features of the ESN software to maximise it value. This is contrast with all the other participant organisations that were struggling to identify value and use of ESN.

\subsubsection{Instant messaging}

Instant messaging capabilities were well used amongst participant organisations. One participant mentioned that it was used as a 'virtual shoulder tapping' to get quick responses on project work. Another mentioned that it was a great way to collaborate and share documents with people who were located elsewhere. Some of the instant messaging software also had video chatting capabilities. This again was used as conference tools however, a few indicated technical difficulties when video conferencing a large group. When enquired how these tools differed from earlier video conferencing tools, it was indicated that the instant messenger was more comprehensive, had similar features to skype, msn messenger. It had a more social inclination.

In some of the participant organisations these instant messaging tool integrated with office collaboration tools, which made it more integrated with their project and business work. However most organisations did not integrate with their more comprehensive ESN toolset like Yammer. One organisation that did implement Yammer successfully, did have advanced instant messaging capabilities to the extent that these tools could keep in touch with people on the field. The participant mentioned that this integration enabled a more seamless ESN experience in connecting with people.

\subsection{Organisational support}

Most participants were of the view that organisational support was limited. In situations where ESN tools were present there was little training in how to use them. Also participants advised that managers did not necessarily support their time in using ESN tools. One participant said that while Yammer was implemented, it was basically done by a handful of managers, without any clear direction from senior management. Essentially the ESN programme was run by ESN evangelists. As a result not many people used the ESN solution. It was also mentioned that 


\section{EVALUATING THE USER PERCEIVED USEFULNESS OF ENTERPRISE SOCIAL NETWORKING}

since there was not many users, there was limited content. This in turn meant that it was harder to promote ESN without content. As the participant mentioned it was a catch-22 effect. The wider community of this organisation did not see the need to participate as it only had a few users and not much content. Also other members of the organisation used other collaboration and instant messenger tools that did not integrate with the main ESN software Yammer.

In another participant's organisation, a team managed its own Wikipedia site to answer common questions that internal clients often queried. However many of the clients did not use this site, but rather called the team directly. The team did not have the management support and could not take formal action in redirecting the clients to the Wikipedia site. Also internal clients mentioned that the FAQ Wikipedia site was poorly implemented and hard to navigate. The team spent many hours in the development of the site outside normal work hours, and did not feel they efforts where appreciated.

Adam's organisation on the other hand had the full support of the organisational senior management with a strategy outline for ESN use, integration and value creation. Business processes where based around the capabilities of ESN. For instance, rather than sending newsletters, the CIO sent ESN posts to communicate with the organisation. Other members could comment on these posts allowing the CIO to know directly the thoughts and the general feedback. The organisation's senior management encouraged employee ESN participation, unlike other organisations in the interview.

Adam also mentioned that new recruits from younger generation were more eager and savvy with ESN and didn't need much training. For them it was wasn't much of a learning curve. However with recruits from the older generation, the organisation had to convince the value it could provide to users in terms of productivity, career networking and a flatter hierarchy to get ideas across.

\subsection{Challenges}

Participants acknowledged that challenges lay ahead for gaining maximum value out of ESN. Participants were in agreement that organisations needed a clear strategy in the implementation and utilisation of ESN. One participant mentioned that his organisation was unsure how to go about with ESN. So a group of managers got together and evangelised ESN. 


\section{EVALUATING THE USER PERCEIVED USEFULNESS OF ENTERPRISE SOCIAL NETWORKING}

While it had some success, there wasn't much users getting on ESN. This participant felt that organisational strategy and support would be really helpful in getting more people on board. In one of the participant organisation, ESN was defragmented, i.e. some departments had a plethora of ESN tools while other business departments had little ESN capabilities. The participant noted that organisational strategy would have been useful in aligning these defragmented solutions.

Another participant was also on the same vein. He indicated that for ESN to be successful it needs to be well used by the people of the organisation. The participant said

"For this to happen, renegade ESN implementation are not going to work'.

The participant discussed importance of management support in investment, and ESN implementation. Investment in changing people attitudes towards ESN was also key to its success.

This participant also indicated about the importance of organisational culture. The participant felt that in order to really get users engaging on a social context a flatter organisation may be required. He felt his organisation may need a change in organisational culture. The participant however was unsure of to make this change happen.

How to interact with ESN software like Yammer was also a challenge that was talked about during the interviews. Some of the participants knew the technical aspects and features of ESN but on a social context were unsure what to say or how to interact through ESN. Another participant was worried that confidential information may be accidently leaked through to other members. The participant also mentioned that knowledge security could be also be a challenge, both for the individual and the organisaiton.

\subsection{Overcoming Challenges}

Participants were of the view that a clear analysis that outlined organisational value may be helpful in gathering management support. But participants also felt that this analysis needed to be comprehensive, looking into the value it can bring to employees and the long term strategic plan and policies to get there. For instance, organisational culture needs to change, potential policy could include promoting ESN tools through incentives. Training new staff was also 
EVALUATING THE USER PERCEIVED USEFULNESS OF ENTERPRISE SOCIAL NETWORKING

discussed. In particular to train older employees and integrating them to the culture of the organisation.

Some of the participants supported the idea of integrating their daily work processes into ESN tools as a way to encourage its use. One participant mentioned that rather than using email newsletters, employees should post weekly blogs on the ESN site. Another felt that it would make their managers appreciate the work they contribute to ESN. ESN Content was discussed by one of the participants as another way to encourage participation. Good quality content and contacts on ESN has been proven to get employees sign up on ESN in his organisation. More ESN content creators that were socially savvy would be useful in getting people interested.

On the topic of knowledge security, no compelling argument was put forward on how to tackle the issue other than training employees on behavioural aspects of ESN. Participants suggested that organisational security of ESN needs to part of the strategic analysis of ESN.

\section{Discussion}

The research process brought insights into the thinking of the participants on the topic of ESN. Some of them related well to the theoretical underpinnings of the literature review. . This is discussed below:

\subsection{Use of ESN Software}

\subsubsection{Linkedln}

DiMicco et al. (2008) assertion that LinkedIn is a popular professional networking tool for career growth is validated in this research. Majority of the participants used LinkedIn. LinkedIn was used to showcase individual skillset and find potential hires and leads (Archambault \& Grudin, 2012). LinkedIn users tapped on to their colleagues contacts and grow their network further. The focus of this site was gathering a network whilst socialising in a professional manner. Some of the users commented on blogs to showcase their knowledge and experience.

Organisations on the other hand use it as a recruitment tool. This is well supported by earlier research (Caers \& Castelyns, 2010). It is used as a tool to select candidates, screen their professional network and gather other recruitment information. Jobvite (2014) conducted a 
EVALUATING THE USER PERCEIVED USEFULNESS OF ENTERPRISE SOCIAL NETWORKING

survey in U.S for the year 2014. The survey finding supports this research's findings and indicates that LinkedIn is used by organisations to

- Search for candidates (96\%)

- Contact candidates (94\%)

- Keep tabs on potential candidates $(93 \%)$

- Vet candidates pre-interview $(92 \%)$

- Post jobs (91\%)

The survey further provides some reasons as to why more and more organisations are moving to LinkedIn for recruitment. Some the key reasons include:

- 49 percent say the quality of candidates is higher;

- 43 percent say the quantity is higher;

- 60 percent estimate that the value of the hires they make through social media is greater than $\$ 20,000$ annually

\subsubsection{Google+, Facebook}

The research findings suggest that only a limited number of organisations have used Facebook, Google+ in wellington. This could be because of the limited sample data. It could also be that the focus of this research has been on Information technology rather than consumer brands. A more detailed research with a wider sample may be required.

In spite of the limited use, the findings in the research indicate that Facebook and google+ is used to showcase organisational brand. Jobvite (2014) survey is also on the same vein, indicating that $65 \%$ of its respondents use Facebook for branding the organisation. Organisations use Facebook to tap into the millions of Facebook users and showcase their organisation or product, create buzz on new products, develop brand and create customer trust (Chiu, Cheung, \& Lee, 2008; Drury, 2008).

It also aligns with Mangold and Faulds (2009) suggestion that organisations are moving to Facebook for branding because consumers are turning more and more to social media to learn 
EVALUATING THE USER PERCEIVED USEFULNESS OF ENTERPRISE SOCIAL NETWORKING

about brands, consume company information and make purchasing decisions. Consumers also feel that the information from social media is trust worthy (Foux, 2006).

It was highlighted in the interviews that one the participant organisation was having difficulty in promoting its brand in Facebook. While the participant have been unable to provide the exact reasons, a number of reasons can be offered. The quality of engagement with consumers is important (Foux, 2006). A highly traditional marketing dialogue followed by the organisation, can make consumer engagement less exciting and inviting to return. Mangold and Faulds (2009) suggest that consumers need to feel excited, and need talking points that consumers could spread and engage. The organisation's infrequent information update can also be an impediment. It is also suggested that conversations that have a story narrative have powerful impacts and stay longer with consumers. Supporting community events can help build emotional connections with its consumers. Providing exclusivity can also be helpful. Consumers feel special when exclusive sales or promotions are provided only to loyal members. Through these measures the organisation can change from its traditional marketing dialogue and employ new tactics to engage with consumers and promote their brand.

\subsubsection{Yammer and other bespoke software}

The research findings suggests that organisations in NZ have limited uptake on internally

focused ESN software like Yammer. While instant messaging and other collaboration tools have been well used by organisations they do not appear to form a cohesive integration between these software tools. Organisations appear to be unsure of ESN and its capabilities. It appears that organisations are in the initial phase of ESN software implementation and use. Earlier research suggests that it is typical growth pattern where organisation start with a low uptake and gradually increase its use as it gathers momentum (Archambault \& Grudin, 2012). In this research there was a sharp increase in social networking tools from 2008 - 2011. The slow uptake could be attributed to a number of reasons discussed below:

\subsubsection{Productivity}

Archambault and Grudin (2012) research indicated that in 2008 productivity gains or at least the perception of productivity gains in ESN tools were limited. However that changed in 2011. Employees slowly developed skills and insights on how best to use ESN tools and increase productivity. Questions, posted on ESN site usually resulted in prompt answers and suggestions 
EVALUATING THE USER PERCEIVED USEFULNESS OF ENTERPRISE SOCIAL NETWORKING

on how to move forward. ESN tools led to better professional engagement by allowing users to tap into their network of colleagues and getting timely help on work matters. It also allowed them to search for information using these tools.

\subsubsection{Attitudes}

Archambault and Grudin (2012) suggests that during their research, senior management in 2008 did not view social networking as productive for work purposes and felt that it does not have a place in corporate work settings. Employees often felt that use of these tools will be disapproved. This feeling was also shared by one of the participants in our research findings. Managers did not view internal social networking tools like Yammer to be useful as well. However this perception slowly began to change as more and more employees were able to demonstrate productivity. Based on Archambault and Grudin (2012) findings in 2012, managers began to realise ESN capabilities and were not only tolerant but also encouraged use of ESN tools.

As organisations in wellington begin to realise the productivity gains in using ESN tools, it is my hypotheses that management attitudes towards ESN would change from 'Is ESN really productive, Can it deliver?' To yes, ESN is useful for us and it warrants a detailed review and investment. Majority of the organisations in wellington have already taken the first steps by using elements of ESN toolset, like LinkedIn and Instant messenger to improve productivity.

However it may be difficult to fully and thoroughly validate the organisational value of ESN tools with empirical data (Efimova \& Grudin, 2008). Analysts in the 1990s argued that emails were unproductive and its use should be minimised. However, emails were and are indispensable tools of business communication.

\subsubsection{Usefulness of Yammer}

It has been difficult to collect comprehensive data on the perceived usefulness of Yammer as only three organisations in the research findings have implemented Yammer or other bespoke solution. However the participants of these organisations were knowledgeable and have provided useful information. Some of the other participants indicated that they are currently analysing ESN tools. These participants have also been quite useful in providing their perceptions on how useful ESN can be in the workplace. 
EVALUATING THE USER PERCEIVED USEFULNESS OF ENTERPRISE SOCIAL NETWORKING

\subsubsection{Codifying tacit knowledge}

Some of the participants noted that ESN was useful in documenting their conversations that could be shared and further discussed. The literature identifies with this notion (DiMicco et al., 2008). Given the social context, ESN with its features and toolset enables a seamless capture of social conversations that can later be shared, discussed and added to the repository of knowledge. It also helps validate the notion made earlier in the literature review that ESN has the capability to codify the social water cooler conversations that traditional knowledge management attempted but didn't do a good job with its structured process.

\subsubsection{Community Feel}

Participants also discussed the community feel that ESN tool facilitated amongst its users. Community feel can be a source of encouragement to social interactions using software like Yammer (Majchrzak, 2007). This social feel can further strengthen bonds and instil community growth. However, based on our research findings while social feel was mentioned, communication was largely work related and personal connections were limited. This could be due to the fact that ESN is just being recently introduced and that its users are familiarising with the toolset (Archambault \& Grudin, 2012). In order to facilitate the community feel it is also noted that the organisational culture plays a role. Strong hierarchal structures form a barrier and weaken the ability to build relationships (DiMicco et al., 2008). One of the participants did acknowledge this stating that ESN works well in a flatter organisation and management hierarchy can be an impediment.

\subsubsection{Integration}

The research findings suggest that organisations in wellington are utilising external ESN tools like LinkedIn and Facebook to create value. LinkedIn is a popular tool that organisations in wellington are increasingly using to gain value in recruitment. This aligns with Li and Bernoff (2011) notion that ESN tools, whether external or internal to the organisation; has the flexibility to socialise and gather knowledge for specific business functions like marketing, sales and human resource management.

However internal ESN integration with external ESN tools has not been evidenced. Majority of the researched organisations have not integrated LinkedIn with internal ESN tools whether it is Yammer or other bespoke ESN software. It is logical to assume that given the 
EVALUATING THE USER PERCEIVED USEFULNESS OF ENTERPRISE SOCIAL NETWORKING

limited and recent implementation of Yammer or other similar software, organisations may need more time to validate the integration benefits.

\subsubsection{Collaboration}

Participants did not appear to have difficulty in using Yammer. The collaborative features were based on Web 2.0 technology with similarities to Facebook features. These features included, posting, commenting, and liking other posts. The theoretical assertion that the use of web 2.0 technology enables quick technical understanding of the features and tools appears to be supported (Kane \& Fichman, 2009). It is also noted that the similarities to Facebook and other social media tools has played a factor in the shorter learning curve.

It would have been interesting to have collected data from a more diverse age group with a balanced combination of young and senior professionals to validate the theoretical assertion that the older generation have more difficulty in coming to grips with the technical aspects and features (Levy, 2009).

Participants did however indicate that they had difficulty in determining how to interact through internal ESN. They were unsure about the boundaries and context of what is appropriate to post or comment. This is surprising as most of the participants were young professionals $25-32$. It appears the assertion by Levy (2009) that the younger generation are more comfortable with professional social media tools is only partly supported. Yes, participant did not have difficulty in understanding the technical nuisances but did have difficulty in determining how to interact, specifically what to comment or post. Archambault and Grudin (2012) suggests that while the younger generation may have technical savviness in understanding ESN tools the older generation are more knowledgeable in utilising ESN for work related tasks, and interact better.

\subsection{Challenges}

\subsubsection{Organisational culture}

Interview Participants have suggested that organisational culture can be a challenge to implementing ESN. An organisation that promotes a flat management would be better equipped to generate value from ESN tools. It has been surprising that participants acknowledged this notion given their limited exposure to ESN tools. This suggests that participants are critically researching and reviewing the current culture of the organisation and its effectiveness in using 


\section{EVALUATING THE USER PERCEIVED USEFULNESS OF ENTERPRISE SOCIAL NETWORKING}

ESN. Social media theorists support this assertion and suggest that a flat management style infuses a sense of self-worth, which in-turn helps build knowledge communities (Brzozowski, 2009; DiMicco et al., 2008; Riemer et al., 2012; Von Krogh, 2012).

One of the participants mentioned that a group of managers took the initiative to implement and popularise Yammer. This suggests that the managers are attempting to introduce change without first aligning with the organisational culture of the organisation. This presents a problem as it conflicts with existing management structures and authority. Organisational wide management support may be required in this instance to help in the dissemination of ESN tools and encourage employees (Brzozowski, 2009).

\subsubsection{Organisational Support}

One of the participants mentioned the importance of organisational support in getting people to use ESN. Brzozowski (2009) suggests that organisational and management support is crucial in changing people mind-sets and influencing a change in culture. It is also useful in outlining the strategy to integrate disparate ESN tools together and form a cohesive social repository of knowledge.

With management support some of the challenges outlined by participants can be minimised. One of the participants mentioned their team developed a Wikipedia site for selfhelp. However many users did not appear to use this site, instead calling the service desk. With management support, users would be better informed about the change in process. Also with management support the team's effort would be recognised and more time and resources would be allocated to improving the site.

In another instance, a participant discussed the difficulty in identifying how to interact with internal ESN tools like Yammer. With management support better self-guides and training could be adopted and help in a smoother transition. Another participant talked about integrating their work processes around ESN so that ESN tool could be leveraged to maximise their efficiency. Changing work processes cannot be accomplished in isolation, as it influences work in other departments and sections of the organisation. Management support can help minimise the obstacles that other departments may have by acting as the intermediary for change. 
EVALUATING THE USER PERCEIVED USEFULNESS OF ENTERPRISE SOCIAL NETWORKING

\subsubsection{Knowledge Security}

Participants have suggested that knowledge security could be a potential issue for the

organisation. Sieg et al. (2010) argues on a similar vein and espouses that when an organisation shares information with external sources to leverage value, it may also inadvertently expose confidential information. Internally, employees may also accidently expose information through internal ESN tools like Yammer. However the consequences in this scenario may not be critical as the information is only leaked within the organisation.

Organisations in wellington are only just implementing ESN. There is little integration of ESN tools with external sources. Consequently, accidental knowledge leaks through external sources may not be much valid. It is more likely that employees may accidently expose confidential information internally within the organisation. While it is apparent that this security issue cannot be completely eliminated, it can be minimised by adequate training.

Organisations in wellington may also have a conflict in knowledge security when dealing with personal information (Sieg et al., 2010). Personal knowledge and information held in blogs, photos and other personal documentation within the internal ESN repository may be deemed as corporate data. However the author or owner of this data especially photos and other personal communication may view it as private information. Training on contextual boundaries of ESN can be useful to minimise this issue i.e. educating users on how to interact, what to mention in posts. Also as the peer ESN community grows internally, it will be in a position to self-advocate with a culture of trust (Von Krogh et al., 2012). The community itself will ensure that content conforms to the organisation's ethical use of personal information and that the organisation and the author /owner of the data will not breach them.

\subsubsection{Knowledge Quality}

ESN Content was briefly discussed by one of the participants. It was mentioned that his organisation lacked quality content that could be used to encourage other non-users to take interest. Chai et al. (2009) agrees that quality of content is vital and further suggests that the accuracy of content and how it is acquired is also important. It is argued that the information may not necessarily be acquired legally and ethically. Von Krogh et al. (2012) on the other hand suggests that peer social practices inherent within ESN will advocate the validation of content. 
EVALUATING THE USER PERCEIVED USEFULNESS OF ENTERPRISE SOCIAL NETWORKING

The particular organisation in wellington currently does not have a well formed peer community to help validate content. As a consequence users may not only feel that content lacks accuracy by also trustworthiness. Content spear headed by few members of senior management would help instil a sense of trust, quality, and accuracy of content.

\section{Limitations}

\subsection{Research Methodology}

The research findings were based only on a small sample data of 7 participants. As a consequence the findings and discussion may only outline a possible trend in Wellington. A more comprehensive research sample may be required to fully validate the findings. This would entail a sample of 20-30 semi structured interviews along with 50-100 participant survey.

\subsection{Research Design}

The four dimensions on which the interview questions were based may not be comprehensive to fully examine the state of ESN use and its perceived usefulness.

\subsection{Research Philosophical Approach}

The anti-positivism philosophical approach adopted in this research has limitations.. The approach can be taxing to the research analyst and risks clouding the understanding of the varied realities of the interviewees. The research analyst could also unknowingly superimpose their own perception of reality. As a consequence, it can be argued that researcher bias may be high with anti-positivism. However given the small sample size, it may not be a serious concern with this research.

Given the subjective nature, anti-positivism is also highly contextual, and not generalisable (Saunders, Saunders, Lewis, \& Thornhill, 2011). However similar research carried in two different social environments may not yield similar results but the results may still be valid within the unique contextual variables. Anti-positivism is also not easily replicable. For instance, if the qualitative interview of this research is repeated twice even with the same exact parameters, it may still yield different results as the interviewees in the second interview have 
EVALUATING THE USER PERCEIVED USEFULNESS OF ENTERPRISE SOCIAL NETWORKING

accumulated the experiences of the first interview and consequently provide a different view point.

\section{Conclusions}

The parallels drawn in the literature review between ESN and KM has been useful in understanding ESN. In particular it has brought focus to the social nature of ESN, use of modern technologies that facilitate unprecedented ease of use. It has also highlighted the community nature of ESN and its importance in managing knowledge security, quality and trust. Lastly it has enabled a better understanding how the community focus builds bond amongst users and encourages knowledge sharing. These dimensions have helped form the basis for the framework of enquiry for this research. It has helped formulate the interview questions to evaluate the user perceptions. The anti- positivism philosophical approach was also useful in peering into user perceptions and make sense of the research findings.

The research findings indicate that users who have had access to ESN, generally have good understanding of the capabilities of ESN. They are eager to learn and use ESN to create efficiencies. Users were largely well versed with LinkedIn. Users also indicated that organisations in wellington also made good use of LinkedIn and instant messaging tools. However internal use of ESN software like Yammer was limited.

The research finding indicate that users generally perceive organisations to be in the initial stages of ESN use. Users do not feel that their organisations fully understand ESN capabilities and also lack drive with little or no ESN strategy in place. Users have indicated a few challenges that their organisation may be facing, including lack of organisational and management support, poor training and lack of quality content. Some users also discussed the need for organisational culture and process change to better use ESN tools. The research findings suggest that while younger users do not need extensive training in the technical understanding of the features, training in contextual understanding i.e. how to interact, what sort of content to post is important. This appear to contradict Levy (2009) assertion that younger generation are more savvy with social tools. 
EVALUATING THE USER PERCEIVED USEFULNESS OF ENTERPRISE SOCIAL NETWORKING

It appears that organisations are slower and less eager than the users with ESN. Consequently it has been difficult to get detailed information on how users use internal ESN tools and for what purpose. This include, perceived productivity gains, career growth opportunities using ESN networking and demonstrating expert knowledge through ESN.

However, there was one organisation in Wellington that has implemented ESN thoroughly. However, as this research is focused on general user perception, the data collected on this organisation has been considered as an anomaly rather than the norm. It is suggested that further case study research on this particular organisation would be helpful in understanding the strategy and challenges overcome by this organisation. This understanding would provide the blueprint for other organisations to successfully implement ESN in wellington.

The challenges discussed in section 5.2 outline the general difficulties organisations in wellington are facing. If organisations can overcome these difficulties, then this research postulates that current poor use of internal ESN could gradually increase as productivity gains are realised by users. This will in turn will influence management attitudes to fully support internal ESN tools infusing further accommodation of internal ESN tools. 
EVALUATING THE USER PERCEIVED USEFULNESS OF ENTERPRISE SOCIAL NETWORKING

\section{References}

Adams, G. L., \& Lamont, B. T. (2003). Knowledge management systems and developing sustainable competitive advantage. Journal of knowledge management, 7(2), 142-154.

Alavi, M., \& Leidner, D. E. (2001). Review: Knowledge management and knowledge management systems: Conceptual foundations and research issues. MIS quarterly, 25(1), 107-136.

Archambault, A., \& Grudin, J. (2012). A longitudinal study of facebook, linkedin, \& twitter use. Paper presented at the Proceedings of the SIGCHI Conference on Human Factors in Computing Systems.

Badii, A., \& Sharif, A. (2003). Information management and knowledge integration for enterprise innovation. Logistics Information Management, 16(2), 145-155.

Bebensee, T., Helms, R., \& Spruit, M. (2012). Exploring Web 2.0 applications as a mean of bolstering up knowledge management. Leading Issues in Social Knowledge Management, 1, 22.

Bloodgood, J. M., \& Salisbury, W. D. (2001). Understanding the influence of organizational change strategies on information technology and knowledge management strategies. Decision support systems, 31(1), 55-69.

Brivot, M. (2011). Controls of knowledge production, sharing and use in bureaucratized professional service firms. Organization studies, 32(4), 489-508.

Brzozowski, M. J. (2009). WaterCooler: exploring an organization through enterprise social media. Paper presented at the Proceedings of the ACM 2009 international conference on Supporting group work.

Caers, R., \& Castelyns, V. (2010). LinkedIn and Facebook in Belgium: the influences and biases of social network sites in recruitment and selection procedures. Social Science Computer Review, 0894439310386567.

Cardinal, L. B., Alessandri, T. M., \& Turner, S. F. (2001). Knowledge codifiability, resources, and sciencebased innovation. Journal of knowledge management, 5(2), 195-204.

Cavusgil, S. T., Calantone, R. J., \& Zhao, Y. (2003). Tacit knowledge transfer and firm innovation capability. Journal of business \& industrial marketing, 18(1), 6-21.

Chai, K., Potdar, V., \& Dillon, T. (2009). Content quality assessment related frameworks for social media Computational Science and Its Applications-ICCSA 2009 (pp. 791-805): Springer.

Chen, J., Zhu, Z., \& Xie, H. Y. (2004). Measuring intellectual capital: a new model and empirical study. Journal of Intellectual capital, 5(1), 195-212.

Chiu, P.-Y., Cheung, C. M., \& Lee, M. K. (2008). Online social networks: Why do "we" use Facebook? The open knowlege society. A computer science and information systems manifesto (pp. 67-74): Springer.

Cross, R., Liedtka, J., \& Weiss, L. (2005). A practical guide to social networks. Harvard Business Review, 83(3), 124-132.

DiMicco, J., Millen, D. R., Geyer, W., Dugan, C., Brownholtz, B., \& Muller, M. (2008). Motivations for social networking at work. Paper presented at the Proceedings of the 2008 ACM conference on Computer supported cooperative work.

Drury, G. (2008). Opinion piece: Social media: Should marketers engage and how can it be done effectively? Journal of Direct, Data and Digital Marketing Practice, 9(3), 274-277.

Efimova, L., \& Grudin, J. (2008). Crossing boundaries: Digital literacy in enterprises. Digital Literacies: Concepts, policies, practices. New York: Peter Lang.

Emery, P. (1999). Understand knowledge management. e-Business Advisor, 14(19).

Eriksson, P., \& Kovalainen, A. (2008). Qualitative methods in business research: Sage. 


\section{EVALUATING THE USER PERCEIVED USEFULNESS OF ENTERPRISE SOCIAL NETWORKING}

Faraj, S., Jarvenpaa, S. L., \& Majchrzak, A. (2011). Knowledge collaboration in online communities. Organization science, 22(5), 1224-1239.

Foux, G. (2006). Consumer-generated media: Get your customers involved. Brand Strategy, 8, 38-39.

Gloet, M., \& Terziovski, M. (2004). Exploring the relationship between knowledge management practices and innovation performance. Journal of Manufacturing Technology Management, 15(5), 402-409.

Haefliger, S., Monteiro, E., Foray, D., \& Von Krogh, G. (2011). Social software and strategy. Long Range Planning, 44(5), 297-316.

Hansen, M. T., Nohria, N., \& Tierney, T. (2005). What's your strategy for managing knowledge? Knowledge management: critical perspectives on business and management, 77(2), 322.

Hatch, M. J., \& Cunliffe, A. L. (1997). Organisation theory: Oxford: Oxford University Press.

Jeppesen, L. B., \& Frederiksen, L. (2006). Why do users contribute to firm-hosted user communities? The case of computer-controlled music instruments. Organization science, 17(1), 45-63.

Jobvite. (2014). Jobvite's 6th Annual Social Recruiting Survey Results. Retrieved from http://web.jobvite.com/Q313 SocialRecruitingSurvey LandingPage.html

Kane, G. C., \& Fichman, R. G. (2009). The shoemaker's children: using Wikis for information systems teaching, research, and publication (includes comments and editorial note). Management Information Systems Quarterly, 33(1), 3.

Levy, M. (2009). WEB 2.0 implications on knowledge management. Journal of knowledge management, $13(1), 120-134$.

Li, C., \& Bernoff, J. (2011). Groundswell: Winning in a world transformed by social technologies: Harvard Business Press.

Majchrzak, A. (2007). The Promise of Passion of Collective Wisdom... Through Wikis and the Wiki Way. conference paper presented at APQC's 12th Annual Knowledge Management Conference: Knowledge Management \& Innovation, Houston, Tex.

Mangold, W. G., \& Faulds, D. J. (2009). Social media: The new hybrid element of the promotion mix. Business horizons, 52(4), 357-365.

Microsoft. (2014). TechNet Forums. Retrieved from http://social.technet.microsoft.com/Forums/enUS/home

Mozilla. (2014). Get Involved. Retrieved from https://www.mozilla.org/en-US/contribute/

Muljadi, H., Takeda, H., Shakya, A., Kawamoto, S., Kobayashi, S., Fujiyama, A., \& Ando, K. (2006). Semantic wiki as a lightweight knowledge management system The Semantic Web-ASWC 2006 (pp. 65-71): Springer.

Newman, B. (1991). An open discussion of knowledge management. The Knowledge Management Forum archives.

Nonaka, I. (1994). A dynamic theory of organizational knowledge creation. Organization science, 5(1), 14-37.

Nonaka, I., \& Takeuchi, H. (1995). The knowledge-creating company: How Japanese companies create the dynamics of innovation: Oxford university press.

Paroutis, S., \& Al Saleh, A. (2009). Determinants of knowledge sharing using Web 2.0 technologies. Journal of knowledge management, 13(4), 52-63.

Polanyi, M. (1967). The tacit dimension. London: Routledge and Kegan Paul.

Pyka, A. (2002). Innovation networks in economics: from the incentive-based to the knowledge-based approaches. European Journal of Innovation Management, 5(3), 152-163.

Razmerita, L., Kirchner, K., \& Sudzina, F. (2009). Personal knowledge management: The role of Web 2.0 tools for managing knowledge at individual and organisational levels. Online Information Review, 33(6), 1021-1039. 


\section{EVALUATING THE USER PERCEIVED USEFULNESS OF ENTERPRISE SOCIAL NETWORKING}

Riemer, K., Scifleet, P., \& Reddig, R. (2012). Powercrowd: Enterprise social networking in professional service work: A case study of Yammer at Deloitte Australia.

Roberts, B. (2008). Social networking at the office. HR Magazine, 53(3), 81-83.

Rodan, S. (2002). Innovation and heterogeneous knowledge in managerial contact networks. Journal of knowledge management, 6(2), 152-163.

Ruggles, R., \& Little, R. (1997). Knowledge management and innovation: an initial exploration. Center for Business Innovationism.

Santosus, M., \& Surmacz, J. (2001). The ABCs of knowledge management. CIO Magazine, 23.

Saunders, M. N., Saunders, M., Lewis, P., \& Thornhill, A. (2011). Research methods for business students, 5/e: Pearson Education India.

Scarbrough, H. (2003). Knowledge management, HRM and the innovation process. International Journal of Manpower, 24(5), 501-516.

Serenko, A., \& Bontis, N. (2004). Meta-review of knowledge management and intellectual capital literature: Citation impact and research productivity rankings. Knowledge and process management, 11(3), 185-198.

Shani, A. B. R., Sena, J. A., \& Olin, T. (2003). Knowledge management and new product development: a study of two companies. European Journal of Innovation Management, 6(3), 137-149.

Sieg, J. H., Wallin, M. W., \& Von Krogh, G. (2010). Managerial challenges in open innovation: a study of innovation intermediation in the chemical industry. R\&d Management, 40(3), 281-291.

SilverStripe. (2014). SilverStripe Developer Network. Retrieved from http://www.silverstripe.org/silverstripe-developer-network/

Venkatesh, V., Morris, M. G., Davis, G. B., \& Davis, F. D. (2003). User acceptance of information technology: Toward a unified view. MIS quarterly, 27(3), 425-478.

Von Krogh, G. (2012). How does social software change knowledge management? Toward a strategic research agenda. The Journal of Strategic Information Systems, 21(2), 154-164.

Von Krogh, G., Haefliger, S., Spaeth, S., \& Wallin, M. W. (2012). Carrots and rainbows: Motivation and social practice in open source software development. MIS quarterly, 36(2), 649-676.

Yammer. (2014). Yammer. Retrieved from https://www.yammer.com/

Zeleny, M. (1987). Management support systems: towards integrated knowledge management. Human systems management, 7(1), 59-70. 
EVALUATING THE USER PERCEIVED USEFULNESS OF ENTERPRISE SOCIAL NETWORKING

\section{Appendix 1}

\section{Participant Information Sheet}

\section{Research Project Title: Evaluating the perceived usefulness of enterprise social networking \\ Researcher: Naveen Vaseegaran, School of Information Management, Victoria University of Wellington}

As part of the completion of my Masters in Information Management, this study is designed to evaluate the perceived usefulness of enterprise social networking with the private and public sector of Wellington NZ.

The research paper aims to identify user perceived usefulness of enterprise social networking within the public and private sector of Wellington NZ. The outcome of this study is to better understand contemporary views on the topic and shape future direction in better dissemination of enterprise social networking in the local industry.

Victoria University requires, and has granted, approval from the School's Human Ethics Committee.

I am inviting professionals working in the private and public sector to participate in this research. Participants will be asked to take part in a 30 minute interview. Permission will be asked to record the interview, and a transcript of the interview will be sent to participants for checking.

Participation is voluntary and confidential. You and the organisation you work for will not be identified personally in any written report produced as a result of this research, including possible publication in academic conferences and journals. All material collected will be kept confidential, and will be viewed only by myself and my supervisor Dr Tony Hooper. The research report will be submitted for marking to the School of Information Management, and subsequently deposited in the University Library. Should any participant wish to withdraw from the project, they may do so until $15^{\text {th }}$ of September 2014 and the data collected up to that point will be destroyed. All data collected from participants will be destroyed within 2 years after the completion of the project.

If you have any questions or would like to receive further information about the project, please contact me at vaseegnave@myvuw.ac.nz or telephone 02102479485 , or you may contact my supervisor Tony Hooper at tony.hooper@vuw.ac.nz or telephone 463-5015. 
EVALUATING THE USER PERCEIVED USEFULNESS OF ENTERPRISE SOCIAL NETWORKING

Naveen Vaseegaran 


\section{Appendix 2}

\section{Participant Consent Form}

\section{Research Project Title: Evaluating the perceived usefulness of enterprise social networking \\ Researcher: Naveen Vaseegaran, School of Information Management, Victoria University of Wellington}

I have been given and have understood an explanation of this research project. I have had an opportunity to ask questions and have them answered to my satisfaction.

I understand that I may withdraw myself (or any information I have provided) from this project, without having to give reasons, by e-mailing vaseegnave@myvuw.ac.nz by the $15^{\text {th }}$ of September 2014.

I understand that any information I provide will be kept confidential to the researcher and their supervisor, the published results will not use my name, and that no opinions will be attributed to me in any way that will identify me or the organisation, where I am employed.

I understand that the data I provide will not be used for any other purpose or released to others.

I understand that as this interview is audio recorded, I will have an opportunity to check the transcripts of the interview. The recording and transcripts of the interviews will be erased within 2 years after the conclusion of the project.

I also understand that a summary of the key findings will be sent if requested. The research report once published will be publicly available from Victoria University Library, Wellington NZ.

Please indicate (by ticking the boxes below) which of the following apply:

I would like to receive a summary of the key findings of this research when it is completed.

I agree to this interview being audio recorded.

Signed: 
EVALUATING THE USER PERCEIVED USEFULNESS OF ENTERPRISE SOCIAL NETWORKING

\section{Appendix 3}

INTERVIEW SCHEDULE

(RESEARCH TOPIC: Evaluating the perceived usefulness of enterprise social networking)

Questions:

1. What aspects of enterprise social networking tools do you use?

2. What are the benefits to you? How does it help you to do your work better?

3. Explain how social enterprise social networking tools help the organisational objectives?

4. What might be helpful in maximising the benefits of social networking?

5. Where do you think the organisation is heading in delivering those tools?

6. What are some the difficulties if any in using enterprise social networking tools? 


\section{Appendix 4 \\ Interview responses}

\section{Transcript 1}

\section{ESN Use}

Well, professionally I use LinkedIn. I find it great to grow my career within my organisation. A lot of my peers are also in LinkedIn and my organisation. My linkedIn profile helps validate my skills and experience. Within the organisation, we have instant messaging capability. Although it hasn't really taken off. I still talk to most via the phone, shoulder tapping works best for me. I prefer to talk to people in person rather than through computer. What appears to be doing well is our team Wikipedia.

\section{Organisational Use and Support}

For LinkedIn, I guess it's about recruiting the best talent out there that is verifiable. Contacts seem to go a long way in getting that dream job and LinkedIn is a great way of getting and keeping those professional contacts. My organisation is just toying with the idea of ESN. I think it's probably because it's a public sector. Public sector is a bit cautious than the private sector.

\section{Challenges}

I might me the wrong person for the question. Simply put my organisation is just beginning to use ESN. We are in a fledging state. I think senior management is unclear about the benefits but does what to know about it. I also think management wants clear measurable results. Am not sure ESN can deliver that. From what I hear you need to first have a large implementation to have any success. ESN can't start small to be an organisational success.

I know that some public sector organisations are working together to make sense of social networking but we have yet to make strategic inroads. To be honest apart from Wikepia, instant messaging and LinkedIn I can't say our team or the teams I have collaborated have used ESN much.

\section{Overcoming Challenges}

The culture needs to change. As a public sector we are largely hierarchal, and it's a real challenge to move away from that. ESN is really great for flat organisation that thrive on openness but with public sector it's a different story. 
EVALUATING THE USER PERCEIVED USEFULNESS OF ENTERPRISE SOCIAL

NETWORKING

\section{Transcript 2}

\section{ESN Use}

My current organisation is rather limited on ESN. However, my previous organisation has taken ESN on board quite well. Yammer has had good success. Though I didn't had much training in it, it seemed to behave much like Facebook with tweaks here and there and so was easy to learn. I haven't embraced the technology yet but it seems to work. I got to know people from other branches with neat ideas on my project. This wouldn't have otherwise happened. What I also like is that it gives me a voice. Normally I don't get the chance to attend senior management meetings but yammer allows me to voice my views in an intelligent manner.

Instant messaging is also quite helpful when I am working away from office. With phone or emails it's not easy to pass files ideas and collaborate.

\section{Organisational Use and Support}

Organisation X, seems to have taken a concerted effort on ESN. There is a clear strategy outlined, apparently there's also been an academic case study done on the organisation and its ESN use.

I think the idea of ESN is to get us employees all talking on the electronic medium, and grow our intellectual capability and do our job better and more efficiently. I do agree that with Yammer I was able to get my project done better. A yammer colleague suggested I approach person y to discuss my project and that lead worked out well for me.

\section{Challenges}

Organisation $\mathrm{X}$ is actually doing pretty well. Actually it's been on the forefront of this technology. Sometimes people do forget that Yammer is a professional social site and not Facebook. Better culture alignment with these professional networking tools would be good. I think for organisation X making sense of all the ESN data would be the next stage. What I mean is putting the data through algorithms to find useful patterns like, what is the general mood of the organisation? What is talked about the most? Etc.

\section{Overcoming Challenges}

In comparison with other organisations, organisation X has stitched ESN into the corporate business quite well. Other organisations are still trying to make sense of ESN. It terms of implementing algorithms, well the tech team is trying a few things but can't really discuss that in detail. Strategy wise, organisation $\mathrm{X}$ is doing well. 
EVALUATING THE USER PERCEIVED USEFULNESS OF ENTERPRISE SOCIAL

NETWORKING

\section{Transcript 3}

ESN Use

I don't use any of them but my work have Facebook/ twitter/google +

No benefit to me don't help me with my work.

\section{Organisational Use and Support}

My company is a large banking organisation. I can't say we have really got into this whole ESN or maybe it's just me. As a large company it helps to attract younger clients to the business via the adverts.

Perhaps we can offer younger generation with special offers via Facebook. I think they are heading towards that goal by having a less formal approach and putting the human side of the business forward

\section{Challenges}

Not sure

\section{Transcript 4}

ESN Use

Organisation D1 I worked for, have its own Facebook page and I was in charge of it (hotel). I also volunteer with a community organization D2. This organisation too has a Facebook page that I'm also in charge of.

It has no personal benefit to me or for the work I do

\section{Organisational Use and Support}

I think for D1 there is no real benefit. This is due to the nature of the business. D1 is a specialist long to medium term accommodation provider for corporate clients from the IT industry. $98 \%$ of the bookings come through relocation agents, client HR departments or travel agents. So updating Facebook is not much of a benefit for profits or even special discounts being posted on Facebook is a waste of time. Travel agents use online booking systems on which we load special deals. Simple email to company HR departments work better for our regular corporate clients.

Even after many years of having Facebook for D1 we have not received more than100 likes, most of the people who liked it are owners and their families and friends, employees and their family and friends. Got about 10 actual guests have liked it, all of them will not return back to us for years to come as they used us until they found permanent accommodation. 


\section{EVALUATING THE USER PERCEIVED USEFULNESS OF ENTERPRISE SOCIAL NETWORKING}

On the other hand, the D2 has had a huge success in attracting people. This is due to the fact that content gets updated with new community events that come up every month. Every month photos get uploaded on to Facebook, ticket prices and project updates go on all the time. There is always something happening with D2. The community use the service of D2 regularly so information from the Facebook site have a good reach and keep people engaged.

\section{Challenges}

As long as there is hype about Facebook D1 will pay for someone to update it even though there is no real benefit. Facebook is simply a cost. About 2 hours of an employee's weekly hours is used to update Facebook.

D2 is using the Facebook integrated tools to understand its community and deliver content that the community wants.

People sometimes tend to not associate professionalism when it comes to Facebook. We have to continuously remind people that content on Facebook need to be professional as it is a reflection on the company. Another aspect is keeping the content interesting to grab the audience attention

\section{Overcoming Challenges}

I think in order for Facebook to work for D1 and its client base, the frequency of use matter a lot. For D1 I don't think Facebook will ever work.

For D2, engaging with the community by regularly updating photos, providing event information and encouraging people to give feedback will help to maximize the benefits. 
EVALUATING THE USER PERCEIVED USEFULNESS OF ENTERPRISE SOCIAL NETWORKING

\section{Transcript 5}

\section{ESN Use}

Considering the size of the department I work for, we are not into much of Social Networking. However recently we have taken initiatives to bring people on board in discussing project related stuffs within the team. We are still in the evaluation phase, how effective it would be in staff contribution and communicating ideas by using the ESN tools. I realized, rather than engaging people by using ESN, it's more of an informal communication that's' what people prefer here. I do believe sometimes the important conversation get lost when it's not recorded or shared with other stake holders. ESN plays important in it but unfortunately we are lacking in this organisation. The reason might be the fear of confidential information that might get shared at different levels within the organisation or with unintended users.

However one of the aspects of ESN is to start knowing new people within the organisation. There are several other ways, the management has introduced in recent past to do social gathering and team building activities. But as I said we are still far away in embracing technology for socialising staff members.

At certain level within the department, we do use Microsoft Office communicator which kind of very useful. The groups has been created so you can broadcast messages to all the concern staff members. It mainly use by our service desk team who are the first point of contact to the customers. It allows to share messages, files among all the members within the group. However organization doesn't push to use this tool, no strategy in place. It's mainly with the users who wish to use these kind of tools.

Apart from that, our security team recommended to use web meeting tools like 'Cisco Webex', 'Team viewer' which is required to work remotely with external contractors, vendors. I quite frequently make use of these tools and there are several rich feature which allows group of members to join, remotely share desktops, give access to remote person and at the same time all users can watch from different locations. These tools allows chat feature as well as voice which makes it easier to communicate effectively. The real benefit which I can see is without giving direct access to machines to the external contractors or vendors, the work can be accomplished and someone can keep an eye on the ongoing work (Huge security benefits).

\section{Organisational Use and Support}

The organisation is focussed on providing services so that customers can rely on us and we can deliver timely solution for their issues. To achieve the vision, we are making concerted efforts and I can say that technology playing important role. Though we are not using much of ESN at the moment but definitely the future plan to remain more connected with the customers using technology. Certain features of ESN are inbuilt in the applications available for staff member's for example the staff portal can allow you to create groups specifically whether its community, 


\section{EVALUATING THE USER PERCEIVED USEFULNESS OF ENTERPRISE SOCIAL NETWORKING}

sports, Music etc. The interested people can join and start discussing on various topics, share pictures, create events and broadcast messages to all the group members. This I found a good way of socialising yourself and bring on board the people of same interest. I believe somehow this is a good way encourage users to participate more into social activities and in a way, overall benefitting to attain goals of the organisation.

I think at the moment, it is restricted to a unit or within a department. There is no formal strategy in place for authorized use of the tools and introduce it at higher level of organisational hierarchy. I believe, we need to put more efforts in engaging people with technology. I know some people do show resistance in adopting ESN but spreading awareness and advising the benefits/advantages can help bringing more people on board.

Being an Education Institution, there's always a section who are tech savvy and are more willing to use their hands on ESN tools. However a section of people are still happy with the legacy way of communicating on day to day basis. Organisation is in the decision making phase of how to bring change in the culture and introduce technology in all aspects of working and serving the clients.

\section{Challenges}

As I mentioned earlier the tools not formally being brought at organisation level, thus so far there's not much complexities in using it. It's moreover based on who wants what and they are free to use it. However proactively moving towards achieving the organisational objectives, I could say our perception has changed a lot in recent years and want to engage people effectively by making use of technologies. At the moment I can say we are working on implementing such tools to make working environment more casual and at the same it probably helps converting employees tacit knowledge into explicit. 


\section{Transcript 6}

\section{ESN Use}

As a public sector, we need to be really careful with the tools we use. Internally we use instant messenger, office communicator, and Share point for collaboration. Whilst we have access to Facebook, LinkedIn sites we do not have an organisational presence. There is a drive towards collating technical applications across various departments, however the concentration is on core corporate applications. For example, Social CRM, however it is at a very preliminary phase.

Personally, very easy communication to individual person within the organisation. I get answers to my questions instantly. Productivity has increased because responsiveness has improved. SharePoint has also been useful in collaboration not sure if it's an ESN tool though. Whilst I am excited about the prospects of ESN in helping my work, since my organisation is a public sector I don't see any breath of use here. May be in a few years.

\section{Organisational Use and Support}

When we talk about ESN, one of the fundamental principles that is driving all this, is communication -; reaching out and accessing people. With my organisation being in the area of diplomacy and international intelligence, communication and the right information is required at every point in time. Social networking will be very useful here, if used in the right ways. For instance, one the strategies is to be at the right place, at the right time when negotiations are happening, being able to have the right information, to able to make the right decision at that point in time. With proper ESN structures in place, all this can be enabled.

I also think ESN can be really useful between inter-agencies, to share business specific domain knowledge, without the red tape. ESN can generate a lot of value here. There are a number of business functions that are common amongst government agencies, better information flow will make for a more streamlined process, saving time and money. Unlike private organisations we don't have any competition between government agencies so I think there is a lot of scope for sharing specific knowledge amongst the agencies.

Largely it is at its conceptual phase. On a scale of $1-10$, I would say 4 . There needs to be a lot more investigation around ESN, currently there are a number of other priority projects. Given we are a public sector I think it would take probably about 3 to 4 years to realise the organisational benefits.

\section{Challenges}

When we talk about enterprise social networking, it is only effective if it is driven in a wider consensus, there is no use if only a handful within the organisation use it. So there needs to be a culture change for people in moving and adopting that way of working.

On an overall context in New Zealand, the public sector is lagging behind with ESN. I think there is misinterpretation, lack of information to know the capability. It needs to have a 
EVALUATING THE USER PERCEIVED USEFULNESS OF ENTERPRISE SOCIAL NETWORKING

consolidated view of all the government departments to effectively do well and get the best out of it. I think the public sector can learn a bit from the private sector, I think they a bit more focused and have direction.

\section{Overcoming Challenges}

I think having management support does go a long way. With management support there is an organisational drive towards utilising them to its maximum potential. Personally I have seen renegade ESN implementations. While they have supposedly been very useful for the team, they haven't had much success in getting other employees to use it. For instance, the IT team have their own version of Wikipedia for troubleshooting, and online collaboration like sharing your desktop. But to be honest we usually still call them up for troubleshooting, even though the answer is probably in their Wikipedia. I think this is because there is no management support. This behavioural change is really hard without management support.

I also think with Management support there is a proper change process, when these tools are introduced. This enables people to be properly trained and are made aware of the process and behavioural changes that accompany them. I can personally attest to this based on our implementation of office communicator. Office communicator is now well used within our organisation for collaboration and sharing of information.

\section{Transcript 7}

\section{ESN Use}

I use LinkedIn personally, Yammer, Lync for instant messaging, desktop sharing, video chat at work. I use the tools very regularly throughout the day. Lync is good for short communications, things that you want to talk to other people about but you don't want the conversation to be around for a long time. If you post it in yammer it stays online for a long time.

With Yammer, I post comment on other people's posts and share my thoughts at that point in time or put up a link to online material and share that. If I forget where the link is, I can go back to yammer, checkout my own feed and find it. One of the recent features I have found that you can actually email Yammer to post comments, rather than logging into Yammer and typing. It's a good tool to use and makes things easier.

I am willing myself to use it to realise its benefits. Basically it's too early. The other staff aren't engaging with it too much or too often just yet. Rather than getting lots of likes on posts you get one or two if you are lucky and they make only one or two comments. 


\section{Organisational Use and Support}

The organisation really doesn't have a strategy. It just been implemented. Some of the Managers have said 'Hey this available to use, use it'. There are a few key people, like myself that keep publishing content and that seems to get other people started using it as well. It's largely informal but a few managers have said I am only going to publish my content in Yammer, so if you want to read it go to yammer, so a lot of people have signed up that way.

I think it could do more. It really comes down to what the company wants to do with Yammer, What's its purpose? I don't think the purpose is really clear just yet.

\section{Challenges}

Poor engagement, not enough content. Its catch-22, one part you need the content the other part you need people to read the content but people won't come until there is content.

\section{Overcoming Challenges}

Apart from more engagement, I suppose it's just getting content up that is useful for people to read and refer to. There is a weekly newsletter that goes out by email, I think it might be better if they put some of that content into Yammer as a series of posts. That might make it easier for people to refer to. With emails, they go into the inbox and don't last a week or two before you delete them. Whereas with Yammer it will be around a lot longer. 
EVALUATING THE USER PERCEIVED USEFULNESS OF ENTERPRISE SOCIAL NETWORKING

\section{Appendix 5}




\section{Response themes}

\begin{tabular}{|c|c|c|c|}
\hline ESN Use & Organisational Support & Challenges & Overcoming Challenges \\
\hline $\begin{array}{l}\text { Personally I use LinkedIn. It } \\
\text { helps validate skills and } \\
\text { experience. Within the } \\
\text { organisation, we have instant } \\
\text { messaging capability. } \\
\text { Although it hasn't really } \\
\text { taken off. }\end{array}$ & $\begin{array}{l}\text { For LinkedIn, I guess it's about recruiting } \\
\text { the best talent out there that is verifiable. } \\
\text { My organisation is just toying with the } \\
\text { idea of ESN. I think it's probably because } \\
\text { it's a public sector. }\end{array}$ & $\begin{array}{l}\text { Senior management is unclear } \\
\text { about the benefits but does } \\
\text { what to know about it. }\end{array}$ & The culture needs to change. \\
\hline $\begin{array}{l}\text { Yammer has had good } \\
\text { success. I got to know people } \\
\text { from other branches with } \\
\text { neat ideas on my project. } \\
\text { Yammer allows me to voice } \\
\text { my views in an intelligent } \\
\text { manner. } \\
\text { Instant messaging is also } \\
\text { quite helpful when I am } \\
\text { working away from office. } \\
\text { With phone or emails it's not } \\
\text { easy to pass files ideas and } \\
\text { collaborate. }\end{array}$ & $\begin{array}{l}\text { There is a clear strategy outlined } \\
\text { Organisation has stitched ESN into the } \\
\text { corporate business quite well. Other } \\
\text { organisations are still trying to make sense } \\
\text { of ESN. }\end{array}$ & $\begin{array}{l}\text { Sometimes people do forget } \\
\text { that Yammer is a professional } \\
\text { social site and not Facebook. } \\
\text { Better culture alignment with } \\
\text { these professional networking } \\
\text { tools would be good. I think } \\
\text { for organisation X making } \\
\text { sense of all the ESN data would } \\
\text { be the next stage i.e. identifying } \\
\text { patterns like, what is the } \\
\text { general mood of the } \\
\text { organisation?, what is talked } \\
\text { about the most? Etc. }\end{array}$ & $\begin{array}{l}\text { It terms of implementing algorithms, } \\
\text { well the tech team is trying a few } \\
\text { things but can't really discuss that in } \\
\text { detail. }\end{array}$ \\
\hline $\begin{array}{l}\text { Facebook/ twitter/google }+ \text {. } \\
\text { Personally I don't use ESN } \\
\text { tools. As a large company it } \\
\text { helps to attract younger } \\
\text { clients to the business via the } \\
\text { adverts. }\end{array}$ & & & \\
\hline
\end{tabular}




\begin{tabular}{|c|c|c|c|}
\hline $\begin{array}{l}\text { Facebook. Organisation used it } \\
\text { for branding and customer } \\
\text { contact. }\end{array}$ & $\begin{array}{l}\text { Organisation D1 } \\
\text { Poorly implemented and no real value. } \\
\text { Organisation D2 } \\
\text { Good success }\end{array}$ & $\begin{array}{l}\text { Organisation D2 } \\
\text { Quality content and frequent } \\
\text { updates } \\
\text { Deliver content that the } \\
\text { community wants. } \\
\text { People sometimes tend to not } \\
\text { associate professionalism } \\
\text { when it comes to Facebook. }\end{array}$ & $\begin{array}{l}\text { Engaging with the community by } \\
\text { regularly updating photos, providing } \\
\text { event information and encouraging } \\
\text { people to give feedback will help to } \\
\text { maximize the benefits. }\end{array}$ \\
\hline $\begin{array}{l}\text { Still in the evaluation phase. I } \\
\text { do believe sometimes the } \\
\text { important conversation get } \\
\text { lost when it's not recorded or } \\
\text { shared with other stake } \\
\text { holders. ESN plays important } \\
\text { in it .The reason might be the } \\
\text { fear of confidential } \\
\text { information that might get } \\
\text { shared at different levels } \\
\text { However one of the aspects } \\
\text { of ESN is to start knowing } \\
\text { new people within the } \\
\text { organisation } \\
\text { Microsoft Office } \\
\text { communicator which kind of } \\
\text { very useful. web meeting } \\
\text { tools like 'Cisco Webex', } \\
\text { 'Team viewer' . Improves my } \\
\text { productivity }\end{array}$ & $\begin{array}{l}\text { not using much of ESN at the moment but } \\
\text { definitely the future plan } \\
\text { Certain features of ESN are inbuilt in the } \\
\text { applications available for staff member's The } \\
\text { interested people can join and start discussing } \\
\text { on various topics, share pictures, create events } \\
\text { and broadcast messages to all the group } \\
\text { members. I think at the moment, it is } \\
\text { restricted to a unit or within a department. } \\
\text { There is no formal strategy in place for } \\
\text { authorized use of the tools and introduce it at } \\
\text { higher level of organisational hierarchy. I } \\
\text { believe, we need to put more efforts in } \\
\text { engaging people with technology. } \\
\text { Being an Education Institution, there's always } \\
\text { a section who are tech savvy and are more } \\
\text { willing to use their hands on ESN tools. } \\
\text { However a section of people are still happy } \\
\text { with the legacy way of communicating on day } \\
\text { to day basis. Organisation is in the decision } \\
\text { making phase of how to bring change in the }\end{array}$ & $\begin{array}{l}\text { Tools not formally being brought } \\
\text { at organisation level, thus so far } \\
\text { there's not much complexities in } \\
\text { using it. It's based on who wants } \\
\text { what and they are free to use it. }\end{array}$ & \\
\hline
\end{tabular}




\begin{tabular}{|c|c|c|c|}
\hline $\begin{array}{l}\text { it probably helps converting } \\
\text { employees tacit knowledge into } \\
\text { explicit. }\end{array}$ & $\begin{array}{l}\text { culture and introduce technology in all aspects } \\
\text { of working and serving the clients. }\end{array}$ & & \\
\hline $\begin{array}{l}\text { Internally we use instant } \\
\text { messenger, office } \\
\text { communicator, and Share point } \\
\text { for collaboration. Whilst we } \\
\text { have access to Facebook, } \\
\text { LinkedIn sites we do not have } \\
\text { an organisational presence. } \\
\text { There is a drive towards } \\
\text { collating technical applications } \\
\text { across various departments. For } \\
\text { example, Social CRM, however } \\
\text { it is at a very preliminary phase. } \\
\text { Productivity has increased } \\
\text { because responsiveness has } \\
\text { improved. SharePoint has also } \\
\text { been useful in collaboration not } \\
\text { sure if it's an ESN tool though. } \\
\text { Whilst I am excited about the } \\
\text { prospects of ESN in helping my } \\
\text { work, since my organisation is } \\
\text { a public sector I don't see any } \\
\text { breath of use here. May be in a } \\
\text { few years. }\end{array}$ & $\begin{array}{l}\text { Largely it is at its conceptual phase. On a } \\
\text { scale of } 1 \text {-10, I would say } 4 \text {. } \\
\text { Potential ESN Use } \\
\text { One of the fundamental principles that is } \\
\text { driving all this, is communication -; reaching } \\
\text { out and accessing people. Communication and } \\
\text { the right information is required at every point } \\
\text { in time. Social networking will be very useful } \\
\text { here, if used in the right ways. } \\
\text { I also think ESN can be really useful between } \\
\text { inter-agencies, to share business specific } \\
\text { domain knowledge, without the red tape. ESN } \\
\text { can generate a lot of value here. There are a } \\
\text { number of business functions that are } \\
\text { common amongst government agencies, } \\
\text { better information flow will make for a more } \\
\text { streamlined process, saving time and money. } \\
\text { Unlike private organisations we don't have } \\
\text { any competition between government } \\
\text { agencies so I think there is a lot of scope for } \\
\text { sharing specific knowledge amongst the } \\
\text { agencies. }\end{array}$ & $\begin{array}{l}\text { It is only effective if it is } \\
\text { driven in a wider consensus, } \\
\text { there is no use if only a } \\
\text { handful within the } \\
\text { organisation use it. So there } \\
\text { needs to be a culture change } \\
\text { for people in moving and } \\
\text { adopting that way of working. } \\
\text { The public sector is lagging } \\
\text { behind with ESN. I think there } \\
\text { is misinterpretation, lack of } \\
\text { information to know the } \\
\text { capability. It needs to have a } \\
\text { consolidated view of all the } \\
\text { government departments to } \\
\text { effectively do well and get the } \\
\text { best out of it. I think the public } \\
\text { sector can learn a bit from the } \\
\text { private sector, I think they a } \\
\text { bit more focused and have } \\
\text { direction. }\end{array}$ & $\begin{array}{l}\text { I think having management support } \\
\text { does go a long way. With } \\
\text { management support there is an } \\
\text { organisational drive towards utilising } \\
\text { them to its maximum potential. } \\
\text { I also think with Management } \\
\text { support there is a proper change } \\
\text { process, when these tools are } \\
\text { introduced. This enables people to be } \\
\text { properly trained and are made aware } \\
\text { of the process and behavioural } \\
\text { changes that accompany them. I can } \\
\text { personally attest to this based on our } \\
\text { implementation of office } \\
\text { communicator. }\end{array}$ \\
\hline
\end{tabular}




\begin{tabular}{|c|c|c|c|}
\hline $\begin{array}{l}\text { I use LinkedIn personally, } \\
\text { Yammer, Lync for instant } \\
\text { messaging, desktop sharing, } \\
\text { video chat at work. I use the } \\
\text { tools very regularly } \\
\text { throughout the day. Lync is } \\
\text { good for short } \\
\text { communications. With } \\
\text { Yammer, I post comment on } \\
\text { other people's posts and } \\
\text { share my It's a good tool to } \\
\text { use and makes things easier. } \\
\text { I am willing myself to use it } \\
\text { to realise its benefits. } \\
\text { Basically it's too early. }\end{array}$ & $\begin{array}{l}\text { The organisation really doesn't have a } \\
\text { strategy. It just been implemented. Some } \\
\text { of the Managers have said 'Hey this } \\
\text { available to use, use it'. } \\
\text { I think it could do more. It really comes } \\
\text { down to what the company wants to do } \\
\text { with Yammer, What's its purpose? I don't } \\
\text { think the purpose is really clear just yet. }\end{array}$ & $\begin{array}{l}\text { Poor engagement, not enough } \\
\text { content. It's catch-22, one part } \\
\text { you need the content the other } \\
\text { part you need people to read } \\
\text { the content but people won't } \\
\text { come until there is content. }\end{array}$ & $\begin{array}{l}\text { Apart from more engagement, I } \\
\text { suppose it's just getting content up } \\
\text { that is useful for people to read and } \\
\text { refer to. }\end{array}$ \\
\hline
\end{tabular}


